7.

Derecho internacional 

Revista de Derecho

de la Pontificia Universidad Católica de Valparaíso

XXXII (Valparaíso, Chile, $1^{\text {er }}$ Semestre de 2009)

[pp. 487 - 529]

\title{
LA FUNCIÓN DEL DERECHO INTERNACIONAL DE LOS DERECHOS DE LA PERSONA EN LA ARGUMENTACIÓN DE LA JURISPRUDENCIA CONSTITUCIONAL PRÁCTICA Y PRINCIPIOS METODOLÓGICOS
}

["The Rol of International Human Rights Law in the Discourse of Constitutional Jurisprudence: Cases and Methodological Guidelines"]

\author{
Manuel Núñez Poblete* \\ Universidad Católica del Norte
}

\begin{abstract}
RESUMEN
El presente artículo trata sobre la función del Derecho internacional de los derechos humanos en el desarrollo de la justicia constitucional chilena. En la primera parte se describen las tendencias y contradicciones que se observan en la jurisprudencia de los tribunales ordinarios de justicia y del Tribunal Constitucional. La segunda parte propone, desde una perspectiva teórica diversa al conocido discurso sobre la jerarquía de los tratados, algunos principios metodológicos que orientan la utilización de dichas fuentes en la interpretación y argumentación constitucional.
\end{abstract}

\begin{abstract}
This article deals with the role of nternational Human Rights Law in the development of the Chilean constitutional jurisprudence. Firstly, it describes the main patterns and inconsistencies of the jurisprudence of the ordinary tribunals and Constitutional Court. Secondly, the paper proposes -from a theoretical outlook which departs from the narratives of treaty's hierarchy-some methodological guidelines for constitutional interpretation and reasoning.
\end{abstract}

* Doctor en Derecho, Profesor de Derecho constitucional, Universidad Católica del Norte. Correo electrónico: manunez@ucn.cl El presente trabajo forma parte del Proyecto de investigación No 11060399, patrocinado por el Fondo Nacional de Desarrollo Científico y Tecnológico (FONDECYT). Las líneas gruesas de este trabajo fueron expuestas en el "Coloquio sobre jurisprudencia constitucional", organizado por la Facultad de Derecho de la Pontificia Universidad Católica de Valparaíso el 9 y 10 de octubre de 2008. El autor agradece a los profesores asistentes las observaciones y sugerencias. 
Palabras Clave: Derecho internacional de los derechos humanos - jerarquía de los tratados internacionales - justicia constitucional - interpretación constitucional - argumentación
KeY Words: International Human Rights Law - Hierarchy of International Law - Judicial Review - Constitutional Interpretation - Judicial Reasoning.

\section{INTRODUCCIÓN}

El constitucionalismo contemporáneo, por lo menos en Occidente, se caracteriza por la progresiva interrelación entre las fuentes internas y aquello que puede identificarse con el término "Derecho no nacional". Este último término comprende el Derecho internacional, el supranacional y el Derecho y la jurisprudencia comparadas. El constitucionalismo chileno no escapa a esta tendencia, por lo que es fácil advertir cómo nuestros órganos legislativos, administrativos y judiciales desarrollan los mandatos constitucionales a partir de premisas cada vez menos nacionalistas y cada vez más internacionalistas. Este fenómeno se ha ido consolidando con especial fuerza desde principios de la década de los noventa, época en la que junto con restablecer la democracia, se modificó la Constitución introduciendo los tratados internacionales como límite al ejercicio de la soberanía. Si se examina la agenda legislativa del Parlamento chileno desde marzo de 1990, es posible encontrar decenas de leyes aprobadas para dar cumplimiento con el creciente número de convenios internacionales suscritos por Chile. Las tempranas leyes "Cumplido", las modificaciones al régimen de filiación del Código Civil, la creación de servicios públicos destinados a gestionar las demandas de grupos sensibles de la población, como las mujeres y los adultos mayores, la modificación de la legislación laboral en materia sindical y de derechos fundamentales, la sustitución del proceso penal, constituyen algunos de tantos ejemplos. Un fenómeno parecido se advierte en la Administración, tanto en la centralizada como en la descentralizada: la primera promoviendo una política de integración internacional que no conocía la historia nacional y la segunda incorporando en su lenguaje el discurso de los derechos fundamentales y del Derecho internacional de la persona.

El fenómeno de la internacionalización del Derecho constitucional, como otra cara de la llamada globalización, también golpeó las puertas de los tribunales de justicia y de la judicatura constitucional. A partir de la década de los noventa se multiplicó el número de convenios internacionales vigentes en Chile, y se sentaron las bases para abandonar el modelo constitucional insular que había caracterizado al discurso constitucional 
nacional. Esa explosión de fuentes, abonada por la buena recepción que tuvo en el extranjero la política chilena de reinserción ${ }^{1}$ y por las expectativas crecientes de ciertos grupos de presión en la llamada "justicia transicional", planteó el problema de la relación entre el Derecho internacional y el ordenamiento interno. Si bien el problema no era completamente nuevo, el reconocimiento de la competencia de organismos como la Comisión Interamericana de Derechos Humanos y la Corte Interamericana de Derechos Humanos, que alcanzaba el poder de juzgar la validez internacional de la propia Constitución, añadió un matiz que no tenía precedentes en el constitucionalismo de la Carta de 1925 y anteriores.

El presente trabajo pretende describir las principales características de la función de los tratados internacionales en la argumentación judicial, ordinaria y constitucional, con especial atención al período democrático de la Constitución de $1980^{3}$ y, dentro de él, al iniciado tras la reforma constitucional de 2005. Cabe aclarar que el texto no persigue tanto hacer una relación exhaustiva de la jurisprudencia como encuadrar las tendencias generales en un contexto comparativo. Esta revisión permitirá advertir las similitudes y diferencias entre la jurisprudencia de los tribunales ordinarios de justicia y la del Tribunal Constitucional, todo ello desde una perspectiva crítica de la argumentación judicial.

En segundo lugar, la investigación pretende sugerir algunas prevenciones y principios, de orden metodológico, que orienten a los operadores judiciales en la inevitable tarea de fallar con arreglo a lo dispuesto en el artículo $5^{\circ} \mathrm{CPol}$., que ordena reconocer como límites al ejercicio de la soberanía "el respeto a los derechos esenciales que emanan de la naturaleza humana [...] garantizados por esta Constitución y por los tratados internacionales ratificados por Chile y que se encuentren vigentes". Como se demostrará en este trabajo, es posible formular dichos principios metodológicos desde una perspectiva que se aparte, y eventualmente abandone, la conocida polémica en torno a la jerarquía de los tratados en el ordenamiento interno.

Por último, cabe indicar que las prevenciones y principios que sugiere

${ }^{1}$ Y que, entre otros efectos, trajo como consecuencia la sumisión del Estado de Chile a la jurisdicción de la Comisión y la Corte Interamericana de Derechos Humanos.

${ }^{2}$ Expresión que la doctrina utiliza para denominar a los procesos jurisdiccionales que suceden a las violaciones de derechos humanos cometidos por regímenes autoritarios, véase: Teitel, Rudy, Transitional Justice (New York, Oxford University Press, 2000), pp. 11 ss.

${ }^{3}$ Para el período 1981-1989 véase el estupendo trabajo de Bernales, Gerardo, Los tratados internacionales, los derechos fundamentales y la jurisprudencia del periodo 1981-1989, bajo el régimen del artículo $24^{\circ}$ transitorio de la Constitución, en Ius et Praxis 9 (2003) 1, pp. 281-327. 
este trabajo se sustentan en dos premisas que conviene explicitar desde un principio. La primera de ellas sostiene que el constitucionalismo es, esencialmente, una cuestión de límites al poder. Estos límites alcanzan también, como lo enseña la práctica comparada hace más de doscientos años, al propio Derecho legislado. Lo anterior quiere decir que el constitucionalismo fija límites al propio Derecho positivo, sin que se divisen razones para sostener que el Derecho internacional positivo escape a ese propósito. La segunda premisa se relaciona con el contexto general que rodea el ejercicio contemporáneo de la jurisdicción, especialmente la constitucional, y reconoce que los rasgos post modernos del constitucionalismo globalizado, caracterizado por la difusión de sistemas pluralistas de fuentes, desaconsejan las soluciones rígidas basadas en las premisas de la jerarquía y los órdenes piramidales ${ }^{4}$.

\section{LA FUNCIÓN DEL DERECHO INTERNACIONAL DE LA PERSONA EN LA ARGUMENTACIÓN JUDICIAL}

La literatura publicista nacional lleva años discurriendo sobre la jerarquía de los tratados internacionales, con especial referencia a la posición de dichos tratados frente a la Constitución ${ }^{5}$. Últimamente, tras la reforma constitucional introducida por la Ley No 20.050 (DO. de 26 de agosto de 2005), el eje de la discusión parece haberse desplazado hacia la posibilidad de controlar - por vía inaplicabilidad- los tratados internacionales ${ }^{6}$

\footnotetext{
${ }^{4}$ Véase mi trabajo: Una introducción al constitucionalismo postmoderno y al pluralismo constitucional, en Revista Chilena de Derecho 31 (2004) 1, pp. 115-136. Recientemente, Rosenfeld, Michel, Rethinking Constitutional ordering in an Era of Legal and Ideological Pluralism, en International Journal of Constitutional Law 6 (2008) 3-4, pp. 415-455; von Bogdandy, Armin, Pluralism, Direct Effect and the Ultimate Say: On the Relationship between International and Domestic Constitutional Law, en International Journal of Constitutional Law 6 (2008) 3-4, pp. 397-413; y Walker, Neil, Beyond Boundary Disputes and Basic Grids: Mapping the Global Disorder of Normative Orders, en International Journal of Constitutional Law 6 (2008) 3-4, pp. 373-396.

${ }^{5}$ Véanse los números monográficos de la Revista Chilena de Derecho vol. 23 (1996) 2-3, Ius et Praxis 9 (2003) 1 y el Panel de Discusión incorporado en la Revista de Derecho Público 69 (2007) 1, pp. 491-528.

${ }^{6}$ Véase: Ribera Neumann, Teodoro, Los tratados internacionales y su control a posteriori por el Tribunal Constitucional, en Estudios Constitucionales 5 (2007) 1, pp. 89-118. El asunto también se ha discutido en la tramitación del proyecto de ley que modifica la Ley orgánica constitucional del Tribunal Constitucional (Boletín $\mathrm{N}^{\circ}$ 4059-07). De acuerdo al texto contenido en el Informe de la Comisión Mixta de 13 de septiembre de 2008 "[d]e conformidad con el número 1) del artículo 54 de la Constitución Política de la República, no procederá la inaplicabilidad respecto de tratados
} 
o la de utilizar las normas internacionales como parámetro de control de constitucionalidad ${ }^{7}$. Por su parte, la jurisprudencia constitucional, muchas veces de espaldas a la doctrina, discurre sobre dos líneas dispares de argumentación. Una línea de argumentación, sostenida desde los tribunales ordinarios, asume la jerarquía constitucional de los tratados internacionales, por lo menos de aquellos con incidencia sobre los derechos fundamentales. La segunda, afirmada por el Tribunal Constitucional, se resiste sistemáticamente a reconocer jerarquía constitucional a dichos instrumentos, a partir de la preeminencia del principio de supremacía de la Constitución. Como se demostrará a continuación, a partir de estas dos líneas argumentales no es posible dar una respuesta unitaria a la pregunta por la función constitucional de los tratados internacionales en el ordenamiento jurídico chileno.

A continuación se resumirá el desarrollo de las dos líneas jurisprudenciales, para después confrontarlas con una pregunta que, quizá por obvia, ha sido preterida por la doctrina nacional. Esta interrogante puede plantearse del siguiente modo: ¿es necesario seguir planteando la relación entre el ordenamiento nacional y el internacional con el lenguaje de la jerarquía?

\section{La jurisprudencia de los tribunales ordinarios de justicia.}

A pesar de su tendencia hacia la fragmentación de los razonamientos, la reciente jurisprudencia de los tribunales ordinarios de justicia parece inclinarse a favor de una progresiva apertura hacia el Derecho internacional, en particular hacia el Derecho de los derechos humanos. La aplicación del Decreto Ley No 2.191 de 1978 en las causas por homicidio y desapariciones forzadas durante el Gobierno de las Fuerzas Armadas ha sido un terreno fértil para discurrir sobre la relación entre las normas internas y las internacionales ${ }^{8}$. De valor paradigmático son los considerandos $45^{\circ}$ al $47^{\circ}$ de la sentencia de la Corte de Apelaciones de Santiago de 5 de enero

internacionales ratificados por Chile y que se encuentren vigentes" (artículo 47B).

${ }^{7}$ Véase: Nogueira, Humberto, Los derechos contenidos en tratados de derechos humanos como parte del parámetro de constitucionalidad: la sentencia rol $N^{\circ} 786-2007$ del Tribunal Constitucional, en Estudios Constitucionales 5 (2007) 2, pp. 457-466.

${ }^{8}$ Véase la relación que hace Matus, Jean Pierre, Informe pericial ante Corte Interamericana de Derechos Humanos, sobre aplicación jurisprudencial del Derecho ley 2.191 de amnistía, de fecha 19 de abril de 1978, en Ius et Praxis 12 (2006) 1, pp. 275296. También son muy útiles las investigaciones de DíAz Tolosa, Ingrid, Aplicación de los Convenios de Ginebra por los Tribunales de Justicia chilenos, en Revista Chilena de Derecho 33 (2006) 2, pp. 305-327; y PicA, Rodrigo, La Convención Americana de Derechos Humanos y las autoamnistías de los Estados por las violaciones de los derechos humanos. Chile y el caso del DL 2191, en Estudios Constitucionales 3 (2005) 2, pp. 141-161. 
de 2004, rol No 11.821-2003, dictada en la causa por secuestro calificado de Miguel A. Sandoval Rodríguez ${ }^{9}$ y los párrafos $11^{\circ}-13^{\circ}$ del voto del Ministro Muńoz contenido en la sentencia de la Corte Suprema de 3 de octubre de 2006, rol No 2.707-2006, por la que se confirma el fallo de la Corte de Apelaciones de Santiago, de 17 de mayo de 2006, dictado en una causa seguida contra A. Pinochet Ugarte. A estas decisiones hay que agregar las sentencias de la Corte Suprema libradas hacia fines de 2006 y

${ }^{9}$ La sentencia aparece publicada en Ius et Praxis 9 (2003) 2, pp. 237-293. En los citados considerandos se lee: “45. Que, en 1989, se agregó el siguiente inciso segundo al artículo 5 de la Constitución Política de la República: [...] El artículo $5^{\circ}$ le otorga asi, rango constitucional a los tratados que garantizan el respeto a los derechos humanos, concediéndoles una jerarquía mayor que a los demás tratados internacionales, en cuanto regulan los derechos esenciales que emanan de la naturaleza humana; 46. Que, como lo señala Francisco Cumplido C., que intervino en la redacción de la reforma del artículo 5: 'La Constitución de 1980 reforzó el carácter de los derechos humanos en el sistema constitucional chileno. En efecto, el inciso segundo del artículo 5 establece, nada menos, que el ejercicio de la soberanía reconoce como limitación el respeto a los derechos esenciales que emanan de la naturaleza humana. Coloca pues sobre la soberanía a tales derechos. Por su parte, el articulo 1 prescribe que las personas nacen libres e iguales en dignidad $y$ derechos, afirmación contenida en varias Convenciones sobre derechos humanos. Agrega que el Estado está al servicio de la persona humana. En la historia fidedigna de esta disposición constitucional quedó expresa constancia que la protección constitucional se refiere no sólo a los derechos establecidos en ella, sino a todos los que son inherentes a la naturaleza humana, como asimismo se reconoció que tales derechos no sólo son los enumerados en el texto de la Constitución, en los capitulos segundo y tercero, sino también los que formen parte del acervo cultural de la humanidad y que son propios de la naturaleza humana. Por [lo] que resolvimos, entonces, aceptar incorporar expresamente, a lo menos, los derechos contenidos en los tratados internacionales ratificados por Chile y vigentes, además de los garantizados por la Constitución ratificados por Chile y que se encuentren vigentes. Los que negociamos la reforma entendimos que con la frase agregada por ella se lograba que los derechos garantizados por la Constitución y por los tratados ratificados y vigente tuvieran la misma jerarquía en el ordenamiento jurídico. En este sentido incorporábamos los derechos asegurados por los tratados a la Constitución. En segundo término les dábamos a los referidos tratados el carácter de vinculantes para todos los órganos del estado, ya que debían no sólo respetarlos, sino que también promoverlos. Lo incorporado a la Constitución son los derechos sustantivos, no la parte adjetiva del tratado' (Actas de la Comisión de la Nueva Constitución, sesión 203.); 47. Que, de lo expuesto, se concluye que si los tratados de derechos humanos fueron incluidos en la modificación constitucional citada, se infiere que esos últimos necesariamente han de tener una mayor jerarquía en el ordenamiento jurídico nacional, que el resto de los tratados internacionales". Véase el comentario sobre esta sentencia de Nogueira, Humberto, Una senda que merece ser transitada: la sentencia definitiva de casación de la Quinta Sala de la Corte de Apelaciones de Santiago, rol No 11.821-2003, caso Miguel Ángel Sandoval Rodríguez, en Ius et Praxis 9 (2003) 2, pp. 233-236. 
principios de 2007, en los casos conocidos como "Molco Choshuenco"10 y "Guarnición Chena"11, que mantienen la doctrina del valor preferente del Derecho internacional sobre el Derecho nacional, incluyendo en el primero los principios recogidos por el ius cogens internacional o por instrumentos codificados al estilo de los "Convenios de Ginebra", el "Pacto de San José de Costa Rica", el Pacto Internacional de Derechos Civiles y Politicos o ciertas declaraciones aprobadas por resoluciones de la Asamblea General de Naciones Unidas. Llama la atención que algunas de las sentencias anotadas hayan utilizado en su argumentación tratados que no se encuentran vigentes en Chile, como es el caso de la Convención sobre Desaparición Forzada de Personas (Belén de Pará, 1994)12 o el Estatuto de Roma de la Corte Penal Internacional ${ }^{13}$. La explicación de esta forma de aplicación anticipada de las normas internacionales reposaría en los

${ }^{10}$ Corte Suprema, 13 de diciembre de 2006, rol No 559-2004, en Estudios Constitucionales 5 (2007) 1, pp. 551-575; véanse especialmente los considerandos $5^{\circ}, 13^{\circ}$ y $21^{\circ}-23^{\circ}$. Véase el comentario crítico de Salinas Burgos, Hernán, Aplicación del Derecho Internacional al caso Choshuenco: Legalidad y seguridad jurídicas vulneradas, en Fermandois, Arturo - García, José, Sentencias Destacadas 2006. Una mirada desde las políticas públicas (Santiago de Chile, Libertad y Desarrollo, 2007), pp. 103130. Una mirada distinta es la que propone ZúñIga, Francisco, Comentario a la sentencia en el caso Molco. Corte Suprema de 13 de diciembre de 2006, en Estudios Constitucionales 5 (2007) 1, pp. 521-525.

${ }^{11}$ Corte Suprema, 13 de marzo de 2007, rol No 3.125-2004, en Estudios Constitucionales 5 (2007) 1, pp. 533-549, véanse especialmente los considerandos $25^{\circ} \mathrm{y}$ $35^{\circ}-40^{\circ}$.

${ }^{12}$ Corte de Apelaciones de Santiago, 5 de enero de 2004, rol No 11.821-2003, "Miguel Ángel Sandoval Rodríguez", cons. 35: "Que, al ser Chile Estado suscriptor de la Convención sobre Desaparición Forzada de Personas, está obligado por la Convención de Viena, de 1969, sobre el Derecho de los Tratados, que se encuentra incorporada al derecho interno de nuestro pais, a no frustrar, de acuerdo a su articulo 18, el objeto y fin de dicha Convención, antes de su entrada en vigor". Esta Convención había sido previamente declarada inconstitucional, por razones de forma, por Sentencia del Tribunal Constitucional rol No 383 de 5 de septiembre de 2003. Con posterioridad fue puesta en votación en la Cámara de Diputados sin alcanzarse el quórum de ley orgánica necesario según la citada sentencia del Tribunal Constitucional, razón por la cual fue rechazada (véase el Diario de Sesiones de la Cámara de Diputados de 7 de noviembre de 2007, p. 51).

${ }^{13}$ Corte de Apelaciones de Santiago, 11 de diciembre de 2006, rol 10.279-2006, cons. 120: "Al ser Chile signatario del Estatuto de la Corte Penal Internacional, está obligado a no frustrar el objeto y el fin de ese Tratado". A diferencia de la Convención interamericana sobre desaparición de personas, el Estatuto de Roma había sido declarado inconstitucional por razones de fondo en sentencia del Tribunal Constitucional rol No 346 de 8 de abril de 2002. 
principios de ius cogens que ellas recogen o en la obligación estatal de no frustrar el objeto y el fin de dichos instrumentos ${ }^{14}$.

Junto a las sentencias anotadas que, en razón de los hechos que han juzgado, han logrado alguna forma de notoriedad pueden agregarse otras tantas que derechamente han afirmado que los tratados internacionales, en general ${ }^{15}$ o en particular tratándose del PIDCP. ${ }^{16}$, la CADH. ${ }^{17}$ o incluso el Convenio de Varsovia sobre Transporte Aéreo Internacional ${ }^{18}$, poseen rango constitucional. En estas decisiones es posible advertir dos fenómenos más o menos marcados. El primero de ellos consiste en la influencia de los abogados integrantes en el caso de los tribunales colegiados, rasgo que se manifiesta desde las sentencias que a mediados de la década de los noventa redactara el Profesor Humberto Nogueira en los casos por el desaparecimiento de Lumi Videla ${ }^{19}$, Bárbara Uribe y Edwin Van Jurick ${ }^{20}$.

${ }^{14}$ Esta práctica no es exclusiva de Chile; véase: Fatima, Shaheed, Using International Law in Domestic Courts (Oxford \& Portland, Hart, 2005), pp. 164-175. Algo parecido puede decirse del recurso a las normas de ius cogens, véanse Ferdinandusse, Ward, Direct Application of International Criminal Law in National Courts (The Hague, T.M.C. Asser Press, 2006), pp. 181 ss.; y SLYZ, George, International Law in National Courts, en Franck, Thomas -Fox, Gregory (editores), International Law Decisions in National Courts (New York, Transnational Publ., 1996), pp. 88 ss.

${ }^{15}$ Corte de Apelaciones de Antofagasta, 11 de junio de 2008, rol No 103-2008, cons. $3^{\circ}$; y Corte de Apelaciones de Santiago, 31 de enero de 2007, rol No 325-2002, voto disidente del abogado Hugo Llanos (cons. $8^{\circ}$ ).

${ }^{16}$ Véanse Corte de Apelaciones de Santiago, 2 de agosto de 2007, rol No 14.2812006, voto disidente del abogado integrante Nelson Pozo; Corte de Apelaciones de Antofagasta, 30 de noviembre de 2007, rol No 250-2007, que califica al artículo 27 PIDCP. como "norma constitucional" (cons. $6^{\circ}$, redacción del abogado integrante Bernardo Julio); y Corte de Apelaciones de Puerto Montt, 29 de abril de 2008, rol No $126-2008$, cons. $4^{\circ}$.

${ }^{17}$ Corte Suprema, 18 de junio de 2008, rol No 2054-2008, cons. $4^{\circ}$, redactado por el abogado integrante Carlos Künsemüller; y Corte de Apelaciones de Antofagasta, 11 de junio de 2008, rol No $103-2008$, cons. $3^{\circ}$.

${ }^{18}$ Véase la sentencia del $26^{\circ}$ Juzgado Civil de Santiago, 11 de mayo de 2001, "Aetna Chile c. Air France". En el cons. $5^{\circ}$ se lee: "[q] ue habiendo sido ratificado por Chile el Convenio de Varsovia sobre reglas relativas al transporte aéreo internacional, mandado cumplir como ley de la República y publicado en el Diario Oficial de 13 de agosto de 1979, ley especial, de rango constitucional en virtud del articulo $5^{\circ}$ de la Constitución Política del Estado, este sentenciador estima que se aplica sobre las normas establecidas en el Código Aeronáutico en relación con la prescripción de las acciones".La sentencia fue recurrida sin éxito de casación en la forma y en el fondo.

${ }^{19}$ Corte de Apelaciones de Santiago, 26 de septiembre de 1994, rol No 13.5971994.

${ }^{20}$ Corte de Apelaciones de Santiago, 30 de septiembre de 1994, rol No 38.6831994. 
El segundo fenómeno característico consiste en cierta tendencia hacia la inercia en la argumentación a favor del Derecho internacional. En efecto, la invocación del supuesto rango constitucional del Derecho internacional expresado en tratados y principios generales suele ser el acompañamiento inevitable en la argumentación para no dar aplicación a una norma legal interna. Para nuestros jueces no parece fácil evitar la tentación de declarar la superioridad constitucional de los tratados cuando de lo único que se trata es de resolver su aplicación preferente sobre la ley. De esta forma, si se extrae del razonamiento la apelación al carácter constitucional de los tratados internacionales, la decisión sigue siendo la misma en atención al carácter preferente que tiene su aplicación por sobre los mandatos de la ley interna.

En definitiva, en la jurisprudencia de los tribunales ordinarios la apertura hacia las fuentes internacionales es cada vez más eficaz en lo que concierne a la aplicación de aquellos por encima de la legislación interna y más bien retórica en lo que afecta a su relación con la propia Constitución. Este último rasgo se aprecia en la virtual inexistencia de jurisprudencia que haya preferido aplicar el Derecho internacional contra disposición constitucional expresa, o siquiera colmar un aspecto no regulado por la Constitución. Así por ejemplo, si se examina la jurisprudencia sobre derechos no explícitamente reconocidos por la Constitución de 1980, tales como el derecho a la propia imagen o la objeción de conciencia, puede constatarse la preeminencia del Derecho nacional (la Constitución) al momento de configurar su contenido. En cierto sentido, puede decirse que el carácter taxativo de los derechos protegidos por la acción de protección -principal vía de desarrollo jurisprudencial de los derechos fundamentales- juega en contra de la apertura de las fuentes hacia el Derecho internacional.

Una excepción parcial a la tendencia anotada se encuentra en un reciente voto de prevención en materia de indemnización por error judicial, reparación estrechamente regulada por la Constitución chilena. En la sentencia de la Corte Suprema de 1 de julio de 2007, sobre aplicación del artículo 19 No letra i) CPol., la prevención del abogado integrante Domingo Hernández afirmó " [q] ue si bien el texto del artículo 19, $N^{\circ} 7^{\circ}$, letra i) de la Carta Fundamental descarta la posibilidad de extender la reparación del error judicial a otras hipótesis que el procesamiento o la condena injustificadamente erróneos o arbitrarios en sede penal quedando por tanto excluidas medidas de cautela personal como la citación o la detención es lo cierto que la enumeración de los derechos constitucionales no se agota en la mención que hace ese precepto. En efecto, el bloque constitucional de derechos se completa, en nuestro ordenamiento, con aquéllos que se encuentran garantizados por los tratados internacionales ratificados por Chile y vigentes, según la remisión que 
formula el inciso $2^{\circ}$ del artículo $5^{\circ}$ de la señalada Carta, alcance que torna obligatorio recurrir a la consulta del derecho convencional de los tratados a fin de indagar si sus normas complementan o amplian la esfera de protección constitucional'21.

\section{El discurso internacionalista en el Tribunal Constitucional, en particular} tras la reforma de la Ley No 20.050.

A diferencia de lo que acontece con los tribunales ordinarios, y especialmente con la Corte Suprema, la jurisprudencia del Tribunal Constitu-

${ }^{21}$ Corte Suprema, 1 de julio de 2008, rol No 3.815-2006. La sentencia continúa agregando que "2. Que el Pacto internacional de derechos civiles y políticos [...] dispone, en su artículo 10.5: 'Toda persona que haya sido ilegalmente detenida o presa, tendrá el derecho efectivo a obtener reparación'. Esta disposición, naturalmente, importa un compromiso de los Estados Partes de respetar y garantizar tal derecho, asi como una opción de toda persona para interponer un recurso efectivo en caso de violación del mismo, conforme a lo que prescribe el artículo 2 del mismo instrumento internacional. Por su parte, el Derecho Internacional de los Derechos Humanos provee un sistema peculiar de interpretación de sus disposiciones, dentro del cual se insertan los principios de buena fe y del sentido finalista de sus mandatos. Conforme a ellos, un tratado debe interpretarse de buena fe según el sentido que haya de atribuirse a sus términos, en el contexto de éstos y teniendo en cuenta su objeto y fin, según lo ordena el artículo 31.1 de la Convención de Viena sobre Derecho de los tratados, no siendo permitido a los Estados suscriptores incumplir un acuerdo de esta naturaleza invocando para ello su derecho interno, como también lo prescribe el artículo 27 de la citada Convención. En este escenario, ninguna disposición propia del derecho interno nacional podría desconocer o restringir en su esencia el derecho efectivo que el artículo 9.5 del Pacto internacional de derechos civiles y políticos confiere a todas las personas, en el supuesto alli designado, para obtener reparación por las secuelas dañosas anejas a su detención o prisión ilegal. 5. [...] la norma convencional de derecho internacional habilita para requerir reparación efectiva por las detenciones $u$ órdenes de prisión preventiva que se expidan contra un imputado, con tal que sean ilegales, condición que es menos exigente que el error injustificado o la arbitrariedad, cuya existencia debe constatar la Corte como presupuesto para la posterior determinación, en juicio sumario, de la especie y monto de los perjuicios que se persigan, dentro del mecanismo y en las hipótesis previstas en la Constitución. Correlacionando la disposición constitucional con el Pacto internacional de derechos civiles y políticos [...] parece razonable exigir la intervención de este máximo tribunal a fin de sujetar al mismo mecanismo común a todos los eventos de error judicial presunto tanto los contemplados en el artículo $19 N^{\circ} 7^{\circ}$ letra i) como aquéllos previstos en el derecho internacional y, particularmente, en el articulo 9.5 del tratado internacional antes citado ya que esta modalidad procesal no tiene por qué afectar la esencia del derecho a obtener reparación efectiva que el instrumento internacional referido asegura. Empero, exigir que, además, la orden de detención o prisión preventiva ilegal sea injustificadamente errónea o arbitraria para justificar la procedencia de la acción constitucional, importaría adicionar un requisito sustantivo que el derecho internacional no postula, debiendo pues centrarse el examen en la sola circunstancia de la ilegalidad". 
cional ha sido relativamente uniforme. Desde los años ochenta que dicho Tribunal viene afirmando que los tratados internacionales se encuentran sujetos al principio de supremacía de la Constitución y, por lo tanto, en caso de conflicto ceden frente a las normas constitucionales. Como la jurisprudencia de este Tribunal es bastante conocida, sólo cabe recordar los dos fallos más relevantes. Se trata de la sentencia dictada en 1987, con ocasión del requerimiento deducido contra Clodomiro Almeyda, y la sentencia dictada en 2002 controlando sobre el Estatuto de Roma. En la primera de ellas el Tribunal afirmó rotundamente que: "las normas constitucionales, en el orden interno, prevalecen sobre las disposiciones contenidas en los tratados internacionales" 22 . Como se recordará, una de las alegaciones presentadas en esa oportunidad se fundamentaba en la supuesta contradicción entre el antiguo artículo $8^{\circ} \mathrm{CPol}$. (texto anterior a la reforma de la Ley No 18.825 [DO. de 17 de agosto de 1989]) y el Derecho internacional. En la segunda sentencia, el Tribunal resolvió que: "si aplicamos el criterio de interpretación de unidad y coherencia del texto constitucional, es evidente que el artículo $5^{\circ}$, inciso segundo, de la Ley Fundamental, no puede analizarse aisladamente $y$ debe armonizarse con las siguientes disposiciones constitucionales, lo que nos lleva a hacer primar las normas fundamentales sobre las de los tratados internacionales sobre derechos humanos vigentes $y$ ratificados por Chile"23.

Después de la reforma constitucional de la Ley No 20.050 el criterio hermético de nuestro Tribunal Constitucional parece mantenerse ${ }^{24}$, aunque comienzan a advertirse gérmenes de cambio, particularmente en el ámbito de la nueva inaplicabilidad. Dejando a salvo lo afirmado por los votos de los Ministros Correa y Vodanovic, en la sentencia sobre la modificación a la Ley No 20.084: Sobre responsabilidad penal adolescente ${ }^{25}$, el Tribunal

${ }^{22}$ Tribunal Constitucional, 21 de diciembre de 1987, rol № 46, cons. $27^{\circ}$.

${ }^{23}$ Tribunal Constitucional, 8 de abril de 2002, rol No 346, cons. $72^{\circ}$. Véase el comentario crítico de Nogueira, Humberto, Consideraciones sobre el Fallo del Tribunal Constitucional Respecto del Tratado de Roma que Establece la Corte Penal Internacional, en Ius et Praxis 8 (2002) 1, pp. 563-581.

${ }^{24}$ Véase: PeÑa, Marisol, Control de constitucionalidad de los tratados internacionales: la experiencia chilena un año después de la reforma de 2005, en Revista de Derecho Público 69 (2007) 1, pp. 497-501; La misma, Cuatro Estudios de Justicia Constitucional (Santiago de Chile, Cuadernos del Tribunal Constitucional, 2007), pp. 56-72.

${ }^{25}$ Voto separado del ministro Correa Sutil y voto disidente del ministro Hernán Vodanovic a la sentencia de 13 de junio de 2007, rol No 786. Ambos concurren a enjuiciar la compatibilidad de proyecto de ley con la Convención de los derechos del niño. A pesar de proponer conclusiones divergentes, ambos votos coinciden en utilizar el texto y los principios de la Convención de los derechos del niño como parámetro de constitucionalidad. Véase el comentario de Nogueira, Humberto, Los derechos 
ha mostrado su tradicional distanciamiento del Derecho internacional a través de dos prácticas constantes: i) evadiendo derechamente el pronunciamiento, a pesar de ser expresamente requerido para ello; y ii) invocándolo como argumento retórico ad abundantiam. Este distanciamiento muestra una ligera variación tratándose del iii) discurso complementario a la parte dogmática de la Constitución, el que ocasionalmente ha conducido al Tribunal hacia iv) el uso tendencioso de las normas internacionales. A continuación se describirá cada una de estas tendencias, contrastándolas finalmente con la generosa referencia que el Tribunal hace a la literatura y Derecho extranjeros.

a) La evasión. En numerosas ocasiones, particularmente en sede de inaplicabilidad, el Tribunal ha sido requerido para declarar la contradicción entre un precepto legal y un instrumento internacional. Frente a estas argumentaciones, que en alguna ocasión han incluido normas internacionales enteramente ajenas a nuestro país y continente ${ }^{26}$, el Tribunal suele guardar completo silencio. A vía ejemplar pueden consultarse las sentencias roles Nos. 468 (9 de diciembre de 2006), 555 (19 de diciembre de 2006), 591 (11 de enero de 2007), 654 (30 de mayo de 2007), 559 (7 de junio de 2007), 728 (3 de julio de 2007) y 1029 (24 de noviembre de 2008). Una variable expresa o explícita de esta práctica se encuentra en las sentencias roles Nos.568 y 661, ambas de inaplicabilidad, donde la evasión parece adquirir un tono positivo al afirmarse que "[q] ue, como ya se expresó en esta sentencia, las normas constitucionales que se estiman infringidas por el requirente son el artículo $19 N^{\circ} 3$, el artículo 61 y el artículo $5^{\circ}$ de la Constitución Política, artículos de tratados internacionales que se citan y los artículos $4^{\circ}$ y $5^{\circ}$ CPP., que por tratarse de normas de rango legal no son susceptibles de ser consideradas como parámetro de este control'27. Como luego no hay argumentación sobre los tratados, ni sobre el principio internacional de la presunción de inocencia, no queda claro si el juicio calificativo de "normas de rango legal" lo predica el Tribunal también respecto de los tratados internacionales. Aunque la redacción de la sentencia no es completamente clara, debe recordarse que los principios contenidos en las normas citadas

contenidos en tratados de derechos humanos como parte del parámetro de control de constitucionalidad: la sentencia rol $N^{\circ} 786-2007$ del Tribunal Constitucional, en Estudios Constitucionales 5 (2007) 2, pp. 457-466.

${ }^{26}$ Véanse la resoluciones del Consejo de Europa citadas por el requirente y que han quedado registradas en la sentencia de 3 de julio de 2007, rol № 728 .

${ }^{27}$ Tribunal Constitucional, 12 de enero de 2007, rol № 661, cons. $5^{\circ}$. El considerando es del mismo tenor en la sentencia rol No 661, misma fecha. Ambo casos versaban sobre lo mismo, la formalización sin desafuero que permite el artículo 416 inc. $2^{\circ}$ del Código Procesal Penal. 
del Código Procesal Penal, particularmente el artículo 4, han sido tomados precisamente del Derecho internacional. Por ello, sea cual sea el verdadero significado de la consideración transcrita, lo cierto es que, por la forma o el fondo, el principio internacional es descartado del juicio propio de la inaplicabilidad.

b) El recurso retórico "ad abundantiam". Cuando el Tribunal concluye que un precepto legal es enteramente compatible con el texto constitucional no es raro que argumente, a mayor abundamiento, la falta de contradicción con las normas internacionales. Como puede advertirse, esta forma de razonar, a medida que se generaliza, reserva a las normas internacionales una suerte de función residual de "parámetro de conformidad". Como esta última función carece de una contrapartida que permita declarar la inconstitucionalidad por infracción de la norma internacional, si se eliminara la referencia al Derecho internacional la decisión seguiría siendo la misma.

Un buen ejemplo de esta forma de eficacia reducida de las normas internacionales se encuentra en el considerando $25^{\circ}$ de la sentencia rol No 576 de 24 de abril de 2007. En esta causa se requirió la inaplicabilidad de los artículos 12 y 14 de la Ley No 17.322: sobre Normas para la cobranza judicial de cotizaciones, aportes y multas de las instituciones de seguridad social. Rechazando el requerimiento, el Tribunal discurre como si fuese un juez internacional afirmando lo siguiente "[q] ue por lo demás y a mayor abundamiento, contrariamente a lo sostenido por la requirente, el precepto legal en cuestión se encuentra en armonía con los deberes impuestos al Estado en materia de derechos esenciales que emanan de la naturaleza humana, tal como lo ordena el artículo $5^{\circ}$ inciso segundo de la Constitución Política de la República, particularmente respecto de diversos tratados internacionales que prohiben la denominada 'prisión por deudas'. En efecto, el artículo 11 del Pacto internacional de derechos civiles y políticos establece que 'nadie será encarcelado por el sólo hecho de no poder cumplir una obligación contractual', esto es, una deuda emanada de un contrato civil ${ }^{28}$.

${ }^{28}$ Tribunal Constitucional, 24 de abril de 2007, rol № 576. El párrafo continúa citando doctrina internacionalista: "Sobre el punto, la doctrina ha señalado que esto significa que la privación de libertad basada en el incumplimiento de obligaciones legales, sean de derecho privado o público, es aceptable. De modo que cuando un tribunal impone la privación de libertad para compeler al cumplimiento de una obligación legal ello no importa una vulneración de la prohibición de la prisión por deudas (Manfred Nowak, U.N. Covenant on Civil and Political Rights. CCPR Commentary. N.P. Engel, Publisher. Kerl, Strasbourg, Arlington). De este modo, se ha concluido que las obligaciones contractuales a que suelen aludir los pactos internacionales dicen más bien relación con obligaciones civiles emanadas típicamente del derecho privado y no de aquellas establecidas por la ley (Sarah Joseph, Jenny Schultz \& Melissa Castan, The 
En la sentencia rol No 747, sobre inaplicabilidad de diversas normas disciplinarias del Código Orgánico de Tribunales, la CADH. refuerza la argumentación constitucional sobre el significado del principio de tipicidad: "[q] ue lo razonado hasta aqui acerca del modo en que está consagrado el principio de tipicidad no se ve alterado por lo dispuesto en el artículo $9^{\circ}$ de la Convención americana de derechos humanos o "Pacto de San José de Costa Rica", aunque se considerara, como pide la requirente, como parámetro de rango constitucional. [...]. Como puede apreciarse del solo lenguaje de esa norma internacional, ella, al igual que la Carta Fundamental chilena, establece el principio de legalidad -y su componente de tipicidad-en materias penales. Asi, se refiere a delitos, penas, condenados y delincuentes. Ello hace innecesario referirse a la jerarquia de la norma de un tratado que no se contrapone con lo establecido en la Constitución"29.

c) El complemento de la parte dogmática de la Constitución. La función complementaria de los instrumentos internacionales frente al estatuto iusfundamental interno, comienza recién a perfilarse con el desarrollo del nuevo instituto de la inaplicabilidad. La prevención de la Ministro Marisol Peńa, buena conocedora del Derecho internacional, en la sentencia rol No 558, de 5 de junio de 2007, es ilustrativa de esta función: "sin perjuicio del razonamiento efectuado en los considerandos décimo tercero y décimo cuarto de esta sentencia, la razón constitucional por la cual los tribunales que conocen del desafuero de un parlamentario respecto de un delito de acción privada, en conformidad a lo dispuesto en el artículo 416, inciso tercero, del Código Procesal Penal, deben interpretarlo 'en una forma que lo compatibiliza con las garantias de un procedimiento e investigación racionales y justos', radica en el deber que se impone a los órganos del Estado, en el artículo $5^{\circ}$, inciso segundo de la misma, en orden a respetar y promover los derechos que la Carta Fundamental garantiza. [...]. A juicio de esta previniente, la invocación precisa del artículo 50, inciso segundo, de la Carta Fundamental como fundamento superior de la aplicación de las normas pertinentes del Código Procesal Penal que se mencionan en el considerando décimo tercero de esta sentencia, se relaciona estrechamente con un principio hermenéutico propio del ámbito de los derechos fundamentales, según el cual debe privilegiarse aquella interpretación que contenga protecciones mejores o más favorables para la persona, y que constituye una expresión del denominado principio 'pro homine' que, a juicio de algunos autores, ha sido incorporado en la Constitución chilena"30.

International Covenant on Civil and Political Rights. Cases, Materials and Commentary, Second Edition)".

${ }^{29}$ Tribunal Constitucional, 31 de agosto de 2007, rol No 747 , cons. $26^{\circ}$.

${ }^{30}$ Tribunal Constitucional, 5 de junio de 2007, rol No 558, prevención de la ministra Marisol Peña. 
Todavía más interesante es la sentencia rol № 807, de 4 de octubre de 2007, dictada a propósito de la supuesta contradicción entre los artículos 17 letra d) y 19 de la Ley No 18.216: sobre medidas alternativas a penas privativas o restrictivas de libertad y el derecho a la igualdad, por una parte, y la prohibición de la prisión por deudas, por la otra. Lo peculiar de este caso radica en que el requirente de inaplicabilidad hizo descansar su pretensión en tres normas, dos de las cuales tenían el carácter de normas internacionales (el artículo 7.7 de la Convención americana sobre derechos humanos y el artículo 11 del Pacto internacional de derechos civiles y politicos). Enfrentado a resolver si la infracción a las normas internacionales citadas constituía una infracción al artículo $5^{\circ}$ inciso $2^{\circ} \mathrm{CPol}$., el Tribunal procedió a interpretar, tal como si fuese un juez internacional, las normas de la CADH. y el PDCP. concluyendo que entre ellas y las normas impugnadas no había contradicción. No existiendo contradicción con la norma internacional, a juicio del tribunal no cabía pronunciarse sobre sus posibles efectos en materia de inaplicabilidad.

La sentencia rol No 807 encuadra el problema del siguiente modo: "[q] ue, como puede apreciarse de las alegaciones de las partes resumidas en el considerando anterior, para acoger la acción interpuesta resultaría necesario que se verificara una doble condición: en primer lugar, que existiera contradicción entre el artículo 19 de la Ley $N^{o} 18.216$-o más precisamente entre los efectos que produciría la aplicación de ese precepto en la gestión pendiente- $y$ alguna de las normas de derecho internacional invocadas, y que, además, y en segundo lugar, en virtud de lo establecido en el artículo 5o, inciso segundo, de la Carta Fundamental, tal contradicción habilitara a esta Magistratura para declarar inaplicable el precepto legal' (considerando $10^{\circ}$ ). Sin renunciar a pronunciarse a causa del carácter no formalmente constitucional de dos de los tres parámetros invocados, y luego de demostrar la compatibilidad entre la norma legal y las normas internacionales, el Tribunal afirma: "[q]ue, no advirtiéndose contradicción alguna entre los efectos que produciria la aplicación de los preceptos legales impugnados y la norma de derecho internacional que se alega infringida, resulta inoficioso, un ejercicio puramente teórico, impropio de un Tribunal e inconducente para resolver el libelo, razonar acerca de si una eventual contradicción, que en este caso no se verifica, sería suficiente para inaplicar el precepto legal. En consecuencia, esta Magistratura no decidirá en esta causa si, a virtud de lo dispuesto en el inciso segundo del artículo $5^{\circ}$ de la Constitución, el derecho a no sufrir prisión por deudas es uno fundamental que emana de la naturaleza humana y si, por estar contenido en un tratado internacional ratificado por Chile y que se encuentra vigente, es o no apto y suficiente para servir de fundamento para declarar inaplicable un precepto legal' (considerando 18 ${ }^{\circ}$. 
A pesar del esfuerzo que hace el Tribunal para sostener que no hay decisión sobre los efectos de la contradicción entre una ley y un tratado sobre el artículo $5^{\circ}$ inciso $2^{\circ} \mathrm{CPol}$., y sobre la competencia asignada en el 93 No 6 CPol., lo cierto es que en la causa rol No 807, el Tribunal entra derechamente a revisar, en un juicio de constitucionalidad, la supuesta contradicción entre una norma interna y la norma internacional. La decisión final, que sostuvo la falta de contradicción entre la norma nacional y las internacionales, podría invitar a pensar que se trata del mismo recurso ad abundantiam y, por tanto, a querer "ver el vaso medio vacío". Sin embargo, si se estima que el camino para mantener a las normas internacionales en su tradicional sitio de postergación pudo ser bastante más breve (como acontece en los casos reseñados de evasión), es posible pensar que esta nueva forma de argumentar, por lo menos en sede de inaplicabilidad, representa una forma larvada de conexión entre la violación del Derecho internacional de los derechos humanos y el artículo $5^{\circ} \mathrm{CPol}$.

d) Uso y abuso del Derecho internacional: logrando que los tratados digan lo que no dicen. El recurso al Derecho internacional (y también al Derecho comparado) para interpretar la Constitución representa un estupenda vía para enriquecer el discurso constitucional interno y, en definitiva, "desnacionalizar" el Derecho constitucional ${ }^{31}$. Sin embargo, al igual que acontece con las normas nacionales, la interpretación del Derecho no nacional admite manipulaciones deliberadas o involuntarias, que la literatura comparada llama "mal uso" del Derecho internacional o del Derecho comparado ${ }^{32}$. Tal es el caso, a juicio propio, de la segunda sentencia sobre el caso llamado de "La píldora del día después", librada el 18 de abril de $2008^{33}$. Esta sentencia recurre en varias de sus fundamentaciones a la $\mathrm{CADH}$. (en alguna parte lo hace a través de un informe en Derecho, como en el considerando $49^{\circ}$ ), al PIDCP., a la Declaración de derechos humanos, a la Declaración americana de derechos y deberes y las Observaciones generales del Comité de Derechos Humanos, para afirmar que la protección nacional del nasciturus es enteramente coherente con la normativa internacional. En el considerando $56^{\circ}$ de esta larga sentencia se lee, por ejemplo, "[q] ue el derecho a la vida asegurado por el artículo $19 \mathrm{~N}^{\circ}$

${ }^{31}$ Véase. De Búrca, Gráinne - Gerstenberg, Oliver, The Denationalization of Constitutional Law, en Harvard International Law Journal 47 (2006), pp. 243-262.

${ }^{32}$ Alford, Roger, Misusing International Sources to Interpret the Constitution, en American Journal of Comparative Law 98 (2004) 1, pp. 57-69; Carozza, Paolo, Uses and Misuses of Comparative Law in International Human Rights: Some Reflections on the Jurisprudence of the European Court of Human Rights, en The Notre Dame Law Review 73 (1998) 5, pp. 1217-1237.

${ }^{33}$ Tribunal Constitucional, 18 de abril de 2008, rol No 740 . 
1 de la Constitución, en consonancia con el artículo $3^{\circ}$ de la Declaración universal de los derechos humanos; el artículo 6.1 del Pacto internacional de derechos civiles y políticos; el artículo $1^{\circ}$ de la Declaración americana de los derechos y deberes del hombre, y el artículo $4^{\circ}$ de la Convención americana de derechos humanos, asegura a toda persona-incluyendo al nasciturus-el derecho a mantener la vida y a conservarla frente a los demás hombres".

El caso citado es notable, pues por mucho que se concuerde con el deber moral y jurídico de respetar la vida desde el momento de la concepción, es altamente controvertible que desde el Derecho internacional pueda arribarse a una conclusión de esa naturaleza. En efecto, varios de los Estados parte en los instrumentos internacionales citados por el tribunal no habrían estado dispuestos a poner su firma sobre dichos tratados si ellos hubiesen contenido algún pronunciamiento a favor o en contra del aborto. Aunque no es un aspecto que pueda ser tratado en este lugar, cabe recordar que existen pronunciamientos expresos de la Comisión Interamericana de Derechos Humanos (caso "Baby Boy") ${ }^{34}$ en orden a que la Declaración americana no contendría una prohibición del aborto. A dicho pronunciamiento habría que agregar un número importante de informes de órganos de supervisión de tratados internacionales que van precisamente en la dirección contraria, esto es, a favor de una interpretación de los tratados que obliga a reconocer, al menos en ciertos casos, el derecho al aborto como otro derecho humano ${ }^{35}$.

El ejemplo recién anotado recuerda una sentencia del Tribunal Constitucional de Polonia que en 1997 declaró inconstitucional la permisión legal del aborto por razones socio-económicas. Como lo subraya la doctrina, el Tribunal Constitucional polaco argumentó sobre bases internacionales (la Convención de los Derechos del Niño) que difícilmente permiten sustentar las posiciones contrarias al aborto ${ }^{36}$. Lo anterior, antes que for-

${ }^{34}$ Comisión Interamericana de Derechos Humanos, Resolución 23/81, caso No 2.141, 6 de marzo de 1981 .

${ }^{35}$ Véase el reciente trabajo de Zampas, Christina - GHer, Jaime, Abortion as a Human Right-International and Regional Standards, en Human Rights Law Review 8 (2008) 2, pp. 249-294. También es valiosa la investigación de SAntoro, Francesca, El aborto ante el Derecho internacional. Principios emanados de organismos internacionales de derechos humanos y Derecho interno (Memoria de Prueba, Universidad Católica del Norte, Escuela de Derecho, 2007), pp. 27 ss.

${ }^{36}$ Se trata de la sentencia K 26/96 de 28 de mayo de 1997. Véase, agregando otros casos similares, la relación que hace Sonneven, Pál, International Human Rights Standard and the Constitutional Jurisprudence of Transition States en Central and Eastern Europe, en ASIL. Proceedings of the 96 $6^{\text {th }}$ Annual Meeting (Washington, American Society of International Law, 2002), pp. 397 ss.; y ZoLKos, Magdalena, 
talecer la argumentación de una sentencia, la debilita, del mismo modo en que devalúa la función del Derecho internacional como instrumento de fundamentación judicial.

e) Derecho internacional y Derecho comparado en la argumentación judicial. La posición conservadora hacia el Derecho internacional contrasta notoriamente con la extraordinaria apertura que nuestro Tribunal Constitucional ha mostrado hacia el Derecho comparado y la doctrina extranjera. En efecto, es bastante usual que, para fundamentar sus sentencias, el tribunal recurra al Derecho comparado como técnica auxiliar de la interpretación constitucional. La lectura de la jurisprudencia constitucional demuestra que nuestros jueces navegan con soltura en las aguas del Derecho y la doctrina americana y europea (especialmente la alemana y la española). La explicación que podría darse para justificar esta tendencia dual reposaría en la diversa naturaleza de ambas fuentes de argumentación. El recurso a la comparación no sería más que una modalidad, más cercana al Derecho, del argumento de autoridad propio de la retórica. El afirmar que algo significa esto o aquello porque en otras partes se entiende así, no supone reconocer carácter obligatorio al Derecho extranjero. Tampoco supone asumir que siempre y bajo toda circunstancia se interpretará tal o cual institución bajo las mismas premisas comparatistas. De hecho, las influencias de los autores y de las constituciones extranjeras varían en razón del tiempo y las filias de los magistrados, entre otros factores. En cambio, el recurso al Derecho internacional reconoce, o al menos debe reconocer, que la fuente a la cual se remite el tribunal tiene siempre y bajo toda circunstancia el carácter de norma obligatoria.

En todo caso, por sobre las diferencias sustantivas entre el Derecho comparado y el Derecho internacional, cabe apuntar que el recurso a ambas fuentes de argumentación plantea un problema para cuya respuesta es necesario remitirse al mismo lugar: la identidad constitucional de un Estado. Efectivamente, en ambos casos el juez se ve enfrentado a la posibilidad de aplicar una norma foránea de contenido e inspiración eventualmente divergentes, y hasta contrapuestos, con el contenido e inspiración del ordenamiento nacional. Sobre este aspecto, se volverá más abajo (III, 3).

\section{PRINCIPIOS METODOLÓGICOS}

\section{Premisa constitucional: confianza y despotismo.}

Antes de explicar los principios metodológicos que pueden orientar la

Human Rights and Democracy in the Polish Abortion Debates: Concepts, Discourses, Subversions, en Essex Human Rights Review 3 (2006) 1, pp. 6-7. 
función del juez que debe fallar con arreglo a los compromisos internacionales y a las obligaciones internas que resultan del artículo $5^{\circ} \mathrm{CPol}$., conviene volver sobre la premisa desde la cual ellos se formulan. Ella fue confesada en la introducción de este escrito y no es otra que la necesidad de limitar el Derecho positivo como expresión del poder. Como decía el borrador de la Resolución de Kentucky, "confidence is everywhere the parent of despotism", de donde resulta que la misma desconfianza que justifica la existencia de controles hacia la legislación interna, puede predicarse para la legislación externa. Esta desconfianza puede justificarse en varios factores concretos, como la gran distancia con la que se formulan las normas, sus posibilidades de fragmentación o incluso de contradicción, el activismo judicial internacional, el déficit democrático que puede afectar a sus órganos oficiales de interpretación, la tentación por ceder a la influencia de ciertos grupos de presión o las mismas posibilidades de ideologización que afectan al Derecho interno, por mencionar algunos ${ }^{37}$. La concreción de todas o algunas de estas amenazas deteriora en mayor o menor medida la legitimidad misma del Derecho internacional, al tiempo que sacrifica las posibilidades de legisladores y jueces internos para configurar la solución más justa para las particularidades del caso.

Como lo explica Kumm, existe una suerte de presunción a favor del Derecho internacional. En virtud de ella, si existe una regla de Derecho internacional que regule una determinada conducta, el ciudadano tendría una buena razón para actuar de acuerdo con ella. Sin embargo, agrega Kumm, esta presunción es refutada cuando las normas de Derecho internacional desconocen seriamente aquellos principios normativos sobre los cuales se sustenta su legitimidad. De este modo, la fuerza vinculante del Derecho internacional se condicionaría al respeto hacia ciertos principios como la subsidiariedad, la participación, el control y la calidad que ofrecen las soluciones basadas en el Derecho internacional ${ }^{38}$.

${ }^{37}$ Véase: Álvarez, José, International Organizations as Law-Makers (New York, Oxford University Press, 2006), pp. 585 ss.; Meron, Theodor, Human Rights LawMaking in the United Nations. A Critique of Instruments and Process (Oxford, Clarendon Press, 1986), pp. 142 ss., El Mismo, Norm Making and Supervision in International Human Rights: Reflections on Institutional Order, en American Journal of International Law 76 (1982) 4, pp. 754-778.

${ }^{38}$ Kumm, Mattias, The Legitimacy of International Law: A Constitutionalist Framework of Analysis, en The European Journal of International Law 13 (2004) 5, p. 929. Para este profesor, la presunción (que él denomina "presunción de legalidad") a favor de la legitimidad del Derecho internacional se sustenta sobre el principio de subsidiariedad (particularmente relevante en el ámbito jurisdiccional), sobre la adecuada participación y control en el proceso formativo de la norma internacional, y, por último, sobre la calidad de los resultados: "bad outcomes affect the legitimacy of a 
Esta forma de enfrentar la sujeción a la norma internacional no dista mucho del modo de enjuiciar la obediencia a la norma interna. Para ambos casos tiene aplicación la vieja enseñanza de la teoría constitucional según la cual del poder hay que desconfiar, tanto del poder de uno, como del poder de muchos. En clave constitucional contemporánea, habría que añadir: tanto del poder nacional como del internacional. Por ello no es casual que la literatura internacionalista contemporánea haya puesto acento en la necesidad de reforzar la subsidiariedad, expresada en la doctrina del margen de apreciación, como uno de los principios fundamentales del Derecho internacional ${ }^{139}$. Desde la filosofía política, otro tanto puede encontrarse respecto de los límites de la (quizá utópica) democracia cosmopolita, para la que filósofos de la talla de John Rawls han demostrado desconfianza si pretende ser construida sobre principios, entre los cuales se cuentan los jurídicos, universalistas u omnicomprensivos ${ }^{40}$.

Quizá podría objetarse la aplicación de las viejas premisas del constitucionalismo -surgidas al interior del modelo estatal moderno-al problema de las relaciones entre Derecho interno y el Derecho internacional. Podría agregarse que en ello no hay más que la antigua disputa entre monistas y dualistas, expresada bajo una nueva forma del dualismo obsoleto ${ }^{41}$, y que al ser el Derecho internacional un ordenamiento distinto, las contradicciones entre aquél y el ordenamiento jurídico interno deben resolverse con criterios distintos del Derecho interno ${ }^{42}$. Como tampoco es la oportunidad para reeditar la conocida disputa entre dualistas y monistas, en sus diversas manifestaciones, sólo cabe sugerir la posible necesidad de revisar las premisas de ambas posiciones a la luz de lo postmoderno, o de un cuadro

decision and tend to undermine the authority of the decision-maker" (p. 927). Si fallan algunos de estos elementos, la presunción desaparece.

${ }^{39}$ Por todos véase: Carozza, Paolo, Subsidiarity as Structural Principle of International Human Rights Law, en American Journal of International Law 97 (2003) 38, pp. 56 ss.

${ }^{40}$ The Law of Peoples (Cambridge Mass.-London, Harvard University Press, 1999), pp. 80-81, 124-125. Esta parte de la doctrina rawlsiana parece haber encontrado eco positivo en Chile, véase: Ruiz Tagle, Pablo, El derecho de los pueblos y los derechos humanos en el siglo XXI, en Ruiz TAgLe, Pablo - Cristi, Renato, La República en Chile. Teoría y práctica del constitucionalismo en Chile (Santiago de Chile, Lom, 2006), pp. 348-350.

41 "Es anacrónico que a estas alturas de los tiempos y de las relaciones internacionales el dualismo siga convocando adeptos": BIDART, Germán, Jerarquía y prelación de normas en un sistema internacional de derechos humanos, en AA. VV. Liber amicorum. Héctor Fix Zamudio (San José de Costa Rica, Secretaría de la Corte Interamericana de Derechos Humanos, 1998), I, p. 462.

${ }^{42}$ Véase: Cassese, Antonio, Diritto internazionale (Bologna, Il Mulino, 2006), pp. 281 ss. 
de relaciones internacionales que tanto dista del modelo postwestfaliano como del modelo surgido inmediatamente después de la Segunda Guerra Mundial. Este último ha sido precisamente el objeto de las tesis revisionistas del constitucionalismo moderno, que han propuesto relevar la teoría constitucional de ese lecho de Procusto que es el Estado y la soberanía, desarrollando un discurso meta-constitucional y constitucionalmente pluralista que traslada parte de las categorías constitucionales más allá del Estado $^{43}$. En este último discurso, la aplicación del principio jerárquico, propio del monismo y el dualismo, es pospuesta en favor de un discurso pluralista o multi-nivel.

El discurso del pluralismo constitucional renuncia a sostener a priori la existencia de una relación jerárquica entre sistemas, limitando la aplicación de dicho principio a la relación entre normas específicas ${ }^{44}$. Aunque pueda parecer atrevido, y hasta heterodoxo para el jurista más conservador, este enfoque epistemológico incluso llega a sugerir que las rigideces del discurso estrictamente jurídico aconsejan preferir el recurso a la prudencia política por sobre el razonamiento jurídico: "la aceptación de una concepción pluralista de los sistemas jurídicos conlleva el reconocimiento de que no todos los problemas jurídicos pueden ser solucionados jurídicamente. El problema, en principio, no es el de la ausencia de respuestas jurídicas a problemas determinados, sino el de la superfluidad de las respuestas jurídicas [...]. La resolución de tales problemas, o, lo que sería más razonable todavía, evitar que se produzcan, es una cuestión de prudencia y juicio político tanto como jurídico" ${ }^{45}$.

La premisa sobre el carácter limitado del Derecho internacional, y el consecuente nexo con su legitimidad, encuentra apoyo parcial en una sentencia de nuestro Tribunal Constitucional. En un requerimiento de inaplicabilidad presentado contra la letra d) del artículo 17 de la Ley No 18.216 (sobre medidas alternativas a las penas restrictivas o privativas de libertad) se sostuvo que la revocación de los beneficios de cumplimiento alternativo de la condena por no pago de una indemnización de perjuicios

${ }^{43}$ Véase el aporte de WALKer, Neil, Flexibility within a Metaconstitutional Frame: Reflections of the Future of Legal Authority in Europe, en Jean Monnet Working Paper 12 (1999), passim; y The Idea of Constitutional Pluralism, en Modern Law Review 65 (2002), pp. 317-359. También puede consultarse mi trabajo: Una introducción al constitucionalismo postmoderno y al pluralismo constitucional, en Revista Chilena de Derecho 31 (2004) 1, pp. 126 ss.

${ }^{44}$ En este sentido, véase: Mac Cormick, Neil, Beyond the Sovereign State, Modern Law Review 56 (1993), p. 10. Véase también la literatura citada en la nota 4.

${ }^{45}$ Mac Cormick, Neil, La sentencia Maastricht: soberanía ahora, en Debats 55 (1996), p. 29. 
contrariaba la prohibición de prisión por deudas establecida en los artículos 7.7 CADH. y 11 PIDCP. Para responder a este argumento, el Tribunal procedió a determinar el significado de las normas internacionales alegadas por el requirente, desechando la incompatibilidad entre las condiciones fijadas por la ley para acceder o mantener el beneficio, vinculadas con el pago de una indemnización, y la prohibición de la prisión por deudas. En lo que importa a esta investigación, el Tribunal afirmó "[q] ue constituiría un error lógico confundir la causa de la pérdida de la libertad-en la especie el delito- con la condición para mantener un beneficio en el modo de cumplir la sentencia condenatoria que afecta al responsable de tal delito. Una es la causa por la cual se priva de libertad (responsabilidad en el delito judicialmente establecido) y otra es una condición sin la cual no puede mantenerse un beneficio carcelario. Confundir ambas es incurrir en un error lógico que llevaría a darle un sentido y alcance al derecho a no sufrir encarcelamiento por deudas que resulta incompatible con el objeto y fin de la norma contenida en el Pacto internacional. Expandir caprichosamente el alcance de la prohibición de la actividad punitiva estatal terminaria además por hacer perder eficacia a la norma de derecho internacional, cuyo alcance acotado constituye parte de la fuente de su legitimidady de la fuerza de su invocación. Además, expandirla así $y$ de modo contradictorio con sus términos haria más improbable la concesión de beneficios carcelarios condicionados" (cons. $\left.14^{\circ}\right)^{46}$.

Nótese cómo el Tribunal se refiere expresamente a la legitimidad de la norma internacional y la condiciona al carácter limitado de su alcance. De aquí resultaría, en la línea de lo que viene desarrollándose en este texto, que las fuentes internacionales poseen unos límites que, en caso de ser traspasados, deterioran la legitimidad de las mismas. Dicho de otro modo, la legitimidad de las fuentes se mantiene en la medida en que no expanda inadecuadamente su significado y, con ello, su ámbito de aplicación. Desgraciadamente este razonamiento no es coherente con la interpretación extensiva que el Tribunal, algunos meses después de la sentencia anotada, dio a varias normas internacionales en el segundo fallo sobre la Pildora del día después.

\section{La no equivalencia textual, teleológica y axiológica.}

Uno de los errores más comunes en el proceso de argumentación de pretensiones y decisiones constitucionales consiste en asumir que los derechos poseen un lenguaje intercambiable en sede nacional e internacional. Como se sugiere a continuación, el significado de las palabras, incluso de las omisiones normativas, puede no ser el mismo. De esta forma, asignar

${ }^{46}$ Tribunal Constitucional, 4 de octubre de 2007, rol No 807. 
idéntico significado a distintos significantes implicaría subvertir el sentido de alguno de los ordenamientos. Del mismo modo, también pueden resultar distintas las finalidades perseguidas y el fundamento axiológico de cada uno de los ordenamientos. Dada esta diversidad estructural, puede hablarse del enfrentamiento, la ocultación, o la asimilación de dos identidades, que por sus rasgos jurídicos y políticos pueden llamarse "identidades constitucionales".

Las identidades se enfrentan cuando la diferencia se hace patente en un conflicto en el que ambas partes alegan tener la última palabra respecto de la interpretación de un derecho determinado y donde, usualmente, colisionan las visiones antropológicas que se esconden tras derechos del mismo nombre pero diverso significado. Hay ocultamiento cuando, inconsciente o deliberadamente, el operador contrabandea reglas desde un ordenamiento hacia otro, como si fuesen instrumentos fungibles o intercambiables. En este caso, a pretexto de la aparente coincidencia textual, se produce una trasposición desviada de los significados. Por último, hay asimilación cuando quienes poseen el dominio formal del contenido del ordenamiento positivo (jueces y legisladores, principalmente) renuncian a la individualidad propia y deciden resolver sus conflictos de derechos fundamentales con todo el acervo de significados del Derecho internacional.

Por lo que se refiere a la Constitución chilena, no parece que ésta haya optado por un sistema de completa asimilación. Al margen de contener algunas referencias textuales al "orden jurídico chileno" ${ }^{47} \mathrm{o}$ de omitir las cláusulas de estilo sobre la incorporación del Derecho internacional o las normas de ius cogens, es más o menos obvio que el ordenamiento constitucional nacional posee una identidad peculiar que no pocas veces ha entrado en conflicto con las normas y principios del Derecho internacional. Además de los casos conocidos en materia de libertad provisional o de libertad de expresión, es relativamente claro que las Bases de la Institucionalidad resumen una determinada visión del hombre, de la familia, de la sociedad y del Estado que es muy propia y que resulta de nuestra particular historia nacional. La segunda sentencia de la Píldora del día después constituye un ejemplo notable de identidad, por lo menos del modo como la han entendido quienes poseen la autoridad de decidir el significado de las palabras de la Constitución.

La concepción de la vida, el estatuto del que está por nacer, la Constitución de la familia, el arraigo de ciertas religiones, nuestra peculiar

${ }^{47}$ Sobre la que algunos autores, con cierto exceso de confianza, subrayan la individualidad del orden jurídico nacional. Así por ejemplo, Ribera Neumann, Teodoro, Los tratados internacionales y su control a posteriori por el Tribunal Constitucional, en Estudios Constitucionales 5 (2007) 1, pp. 99-101. 
concepción y alcance de la propiedad, constituyen, entre otros, rasgos que construyen nuestra identidad constitucional. Por sobre las formalidades, $o$ las posibles declaraciones expresas acerca de la posición de los tratados en el ordenamiento jurídico interno, estos rasgos son los que verdaderamente construyen la identidad constitucional y lo que potencialmente pueden entrar en fricción con la normativa internacional. Luego, dados estos rasgos, la cuestión de la identidad es un dato, no una opinión. Y frente al dato, corresponde identificar los criterios que permitan filtrar la aplicación del acervo normativo y jurisprudencial de las distintas organizaciones de derechos humanos de las cuales forma parte Chile. El respeto por estos criterios metodológicos, mantendrá a cada ordenamiento dentro de aquellos márgenes que sustentan su legitimidad.

a) El sentido de las palabras. La coincidencia textual no puede servir de pretexto para sostener que el significado de la norma internacional es idéntico al de la norma nacional y viceversa.

La Semiología, la Filosofía del lenguaje, la comparación jurídica y la Historia del Derecho, por mencionar algunas disciplinas, enseñan que es posible que dos textos que dicen lo mismo, no signifiquen necesariamente lo mismo. Como se explicaba más arriba, que el Derecho internacional, en sus diversos instrumentos, reconozca el derecho a la vida con palabras similares o incluso idénticas a las utilizadas por nuestra Constitución no significa necesariamente que ambos instrumentos tengan idéntico significado. La práctica internacional sobre el aborto es cada día más demostrativa de esta disparidad de significados y de la potencial colisión de identidades entre el ordenamiento nacional y el internacional ${ }^{48}$. Esta divergencia de significados no debe llamar la atención pues, contra lo que se cree, la falta de consenso universal sobre ciertos conceptos fundamentales es mayor de lo que se cree. Conceptos tan fundamentales como la vida o la dignidad de la persona son objeto de particulares concepciones y de numerosos disensos más allá de un núcleo común que, dado el caso, puede ser bastante pequeño ${ }^{49}$.

En la definición del sentido de la palabras juega un importante papel la estructura estatista que tienen los mandatos contenidos en los instrumentos internacionales. En efecto, si se trata de mandatos dirigidos a los Estados, el principal obligado por ellos sería el Estado. Luego, trasladar ese lenguaje al discurso constitucional interno, que en Chile asume con mucha naturalidad el efecto horizontal de los derechos (asunción que no

\footnotetext{
${ }^{48}$ Véase la nota 35.

${ }^{49}$ Véase: McCrudden, Christopher, Human Dignity and Judicial Interpretation of Human Rights, en The European Journal of International Law 19 (2008) 4, pp. 697 y ss.
} 
es tan de recibo en otras latitudes), altera el fin de la norma y, con ello, trastorna su significado. Así por ejemplo, las disposiciones sustantivas del PIDCP. no pueden interpretarse aisladamente, esto es, sin tener en cuenta lo que manda el artículo 2 del mismo, en el sentido de indicar que la obligación de respeto y garantía recae sobre los Estados. Explicando este precepto, la Observación general No 31 (aprobada en la 2187.a sesión del Comité de Derechos Humanos) al PIDCP. indica que "el párrafo 1 del articulo 2 estipula que las obligaciones son vinculantes para los Estados y que no producen, como tales, un efecto horizontal directo como cuestión de derecho internacional. El Pacto no puede considerarse como un sustitutivo del Derecho interno penal o civil' (párrafo 8) ${ }^{50}$.

La lectura de la Observación general No 13 derriba otro mito, cual es el de la necesaria aplicabilidad directa de los tratados sobre derechos humanos. En el párrafo 13 de la citada Observación indica que: "[e]l párrafo 2 del artículo 2 impone a los Estados Partes la obligación de adoptar las medidas necesarias para hacer efectivos los derechos del Pacto en la esfera interna. De ello se deduce que, a menos que los derechos del Pacto ya estén protegidos por sus leyes o prácticas internas, los Estados Partes están obligados a introducir en el momento de la ratificación, los cambios de los derechos y prácticas internas que sean necesarios para garantizar su conformidad con el Pacto. [...]. El articulo 2 autoriza a un Estado Parte a proceder de conformidad con su propia estructura constitucional interna $y$, en consecuencia, no exige que el Pacto sea directamente aplicable en los tribunales, mediante la incorporación del Pacto al derecho nacional'.

Del párrafo recién transcrito se desprenden dos consecuencias. En primer lugar, la directa aplicabilidad es aconsejable, pero no imprescindible. De hecho, hay democracias de cuya solidez nadie duda, donde la directa aplicabilidad del Derecho internacional simplemente no existe (como es el caso de varios países de la Commonwealth). En segundo lugar, y de modo coherente con el principio de subsidiariedad, si "los derechos del Pacto ya [están] protegidos por sus leyes o prácticas internas" los Estados no estarían obligados a homologar sus disposiciones internas con dicho instrumento. En este último caso, serían suficientes las normas y prácticas del Derecho interno de acuerdo a su propio significado.

b) El sentido del silencio normativo. En el Derecho internacional de los derechos de la persona la omisión del reconocimiento de un derecho no tiene el mismo sentido que puede atribuirse en el Derecho

\footnotetext{
${ }^{50}$ Cito desde la traducción castellana, NaCiones Unidas, Recopilación de las observaciones generales y recomendaciones generales adoptadas por órganos creados en virtud de tratados de derechos humanos (s.l., HRI/GEN/1/Rev. 7, 2004), p. 226.
} 
interno. Luego, ni los jueces internos ni los jueces internacionales pueden colmar dicho vacío atribuyendo un significado diverso a la sola remisión de la respuesta al Derecho nacional.

Para la teoría constitucional liberal, en materia de libertades, el silencio del legislador obraba siempre en beneficio de la libertad. Lo anterior explicaba, por ejemplo, que la versión original de la Constitución de los Estados Unidos careciera durante una década de una declaración de derechos. En el plano interno, las declaraciones de derechos tendrían un sentido abierto, en cuanto no habría impedimentos para que se reconociesen, especialmente por la vía judicial, los derechos no enumerados en ella. La literatura nacional sobre los derechos fundamentales, en general coincide con este postulado al sostener que la enumeración de derechos del artículo 19 no es taxativa ${ }^{51}$. La libertad y la dignidad del primer artículo de nuestra Constitución servirían de cláusulas abiertas para recibir cualquier derecho no explicitado en el detallado listado de nuestra Constitución ${ }^{52}$. Aunque la práctica no va muy de la mano con este principio ${ }^{53}$, podemos quedarnos con la teoría, según la cual -al menos en principio- no hay en nuestro sistema impedimentos positivos para reconocer derechos no positivados.

En el Derecho internacional convencional de los derechos humanos, en cambio, las cosas no son tan sencillas ${ }^{54}$. Aunque la doctrina y la jurisprudencia internacional subrayan la condición especial de los tratados de derechos humanos frente a la generalidad de las convenciones internacionales

${ }^{51}$ Silva Bascuñán, Alejandro, Tratado de Derecho constitucional (2a edición, Santiago, Editorial Jurídica de Chile, 2006), XI, p. 26; Verdugo, Mario - Pfeffer, Emilio - Nogueira, Humberto, Derecho constitucional (Santiago, Editorial Jurídica de Chile, 1994), I, p. 188; y CEA Egaña, José Luis, Derecho constitucional chileno (Santiago de Chile, Ediciones Universidad Católica, 2004), II, p. 49.

${ }^{52}$ En este sentido, Ríos, Lautaro, La dignidad de la persona, en VV.AA., XXV Jornadas Chilenas de Derecho Público. La dignidad de la persona (Valparaíso Edeval, 2006), I, pp. 51-52.

${ }^{53}$ En efecto, si se examina la jurisprudencia nacional sobre derechos no reconocidos el resultado es más bien decepcionante. $\mathrm{O}$ los derechos se niegan (como acontece con la objeción de conciencia frente al servicio militar), o simplemente se subsumen en la generosísima propiedad (como ha sucedido más de alguna vez con el derecho a la imagen).

${ }^{54}$ En general, véanse: BIDART, Germán, Los derechos 'no enumerados' en su relación con el Derecho constitucional y el Derecho internacional, en MÉNDEZ, Ricardo (coord.), Derecho internacional de los derechos humanos. Memoria del VII Congreso Iberoamericano de Derecho constitucional (México D.F., Instituto de Investigaciones Jurídicas UNAM, 2002), pp. 103-113; Gros, Héctor, Los derechos humanos no enunciados o no enumerados en el constitucionalismo americano y en el artículo 29.c) de la Convención Americana sobre derechos humanos, en Anuario Iberoamericano de Justicia Constitucional 4 (2000), pp. 145-172. 
(ausencia de reciprocidad, restricción de la capacidad de formular reservas, etc. $)^{55}$, lo cierto es que el campo creador de los jueces internacionales de derechos humanos es bastante más reducido que el de los jueces nacionales. En este sentido no cabe malinterpretar las cláusulas abiertas al estilo del artículo 5.2 PIDCP. o 29 CADH., pues lo que ellas quieren decir es que, a pretexto del silencio de alguno de esos instrumentos, no puede negarse la existencia de otros derechos no codificados. En este sentido cabe recordar que la jurisprudencia internacional se encuentra limitada por el texto de un modo mucho más grave que el juez nacional. En efecto, si bien es cierto que a partir de los textos es posible defender una interpretación evolutiva, que adecue los textos "vivos [...] a la evolución de los tiempo y, en particular, a las condiciones de vida actuales" 56 , ello no significa un desprecio total por el método positivo en la interpretación de dichos instrumentos.

A diferencia de lo que puede suceder en el orden nacional, el silencio de los tratados refleja muchas veces la falta de consenso sobre lo universal. En este sentido, hay que reconocer que, a pesar de todas las críticas que durante el siglo XX se han formulado al consensualismo o voluntarismo en la doctrina internacionalista (los Estados no se obligan sino en la medida de su propia voluntad) ${ }^{57}$, en el lenguaje moral o de valores que se esconde tras el discurso de los derechos radica un importante argumento en favor del consentimiento expresado en los instrumentos internacionales. Dicho de otro modo, lo no explicitado es, muchas veces, la condición para que un Estado suscriba un instrumento. Aspectos críticos, tales como la eutanasia, el aborto, la pena de muerte, la constitución de la familia, la configuración del matrimonio o la objeción de conciencia, entre tantos otros, permanecen en el dominio de la legislación constitucional o sub-constitucinal interna. En consecuencia, pretender que el tratado dice algo allí donde guarda silencio es tan grave como subvertir el significado de sus palabras.

La práctica del sistema interamericano confirma esta tesis. Además de los casos ya citados sobre el aborto, pueden agregarse los casos "Bomchil" y "Sahli". En el caso "Bomchil y otros", la Comisión Interamericana resolvió que "[n] o es aceptable el argumento de los peticionarios de interpretar

${ }^{55}$ Véase: Quel, Francisco, La protección internacional de los derechos humanos: aspectos generales, en Fernández de Casadevante, Carlos (coord.), Derecho internacional de los derechos humanos (Madrid, Dilex, 2007), pp. 100 ss.

${ }^{56}$ Corte Interamericana de Derechos Humanos, 31 de agosto de 2001, "Caso de la Comunidad Mayagna (Sumo) Awas Tingni vs. Nicaragua” (sentencia de fondo, reparaciones y costas), ap. 146.

${ }^{57}$ Véase con provecho Koskenniemi, Marti, From Apology to Utopia. The Structure of International Legal Argument (Cambridge, Cambridge University Press, 2005), pp. 309. 
como incorporados a la Convención 'todos los derechos consagrados en la Declaración Americana de los Derechos y Deberes del Hombre por la vía del Artículo $1^{\circ}$, inciso 2 del Estatuto de la Comisión Interamericana de Derechos Humanos, estén o no incorporados a aquella', pues esto no se aviene con las normas sobre interpretación de tratados del Artículo 31, inciso 2 de la Convención de Viena sobre Derecho de los Tratados (1969), de la cual la República Argentina es Estado Parte, ya que no existe acuerdo o instrumento formulado o concertado entre los Estados Partes en la Convención Americana a los efectos de hacer valer la Declaración americana de los derechos y deberes del hombre (1948) como parte integrante de la Convención o suplementaria de la misma para los Estados Partes". Más adelante, el mismo párrafo agrega: "es regla de interpretación la que establece que 'se debe presumir que el texto del tratado es expresión auténtica de la intención de las partes', tal como lo señaló la Comisión de Derecho Internacional en el examen del proyecto de la Convención sobre esa materia. Resulta que el texto de la Convención es claro sobre cuáles son los derechos protegidos por ella y, por tanto, razón de más para no hacer lugar a la referida interpretación de los peticionarios" 58 .

Más recientemente, en el caso "Sahli Vera y otros", la Comisión Interamericana sostuvo que: "La Convención Americana no crea y ni siquiera menciona expresamente el derecho de 'objeción de conciencia', el alegado derecho a no ser obligado a cumplir, por razones de conciencia, las imposiciones de la ley. El término 'objetores de conciencia' sólo aparece una vez en la Convención Americana. En el artículo 12, que establece el derecho a la libertad de conciencia y religión, no se hace mención explicita al término objeción de conciencia', sino que se hace referencia al mismo en el articulo que define el trabajo forzado u obligatorio. El artículo 6 de la Convención Americana define el derecho a ser libre de la esclavitud o de la servidumbre involuntaria, y el articulo 6(3)(b), siguiendo el Convenio $N^{\circ} 29$ de la OIT sobre la misma materia, expresamente excluye de la definición de trabajo forzado o compulsivo el 'servicio militar y, en los paises que reconocen a los objetores de conciencia, el servicio nacional que la ley prevea en lugar del servicio militar'. [...]. En suma, y conforme al análisis resumido que se realiza a continuación, la jurisprudencia internacional de derechos humanos reconoce la condición de objetor de conciencia en los paises que prevén dicha condición en sus leyes nacionales. En los paises que no prevén la condición de objetor de conciencia, los órganos internacionales de derechos humanos concluyen que no existe violación del derecho a la libertad de pensamiento, conciencia o religión" 59 .

${ }^{58}$ Comisión Interamericana de Derechos Humanos, 30 de marzo de 1988, Informe sobre los casos 9.777 y 9.718 , párrafo 6 .

${ }^{59}$ Comisión Interamericana de Derechos Humanos, 10 de marzo de 2005, Informe 43/05 sobre el caso 12.219, párrafos 37-38. 
c) Los fines. Los derechos reconocidos en los instrumentos internacionales carecen, en principio, del efecto horizontal. Por esta razón, limitan en forma secundaria la autonomía de los individuos y en forma primaria la competencia de los órganos del Estado. En consecuencia, cuando el juez juzga la actividad de un órgano administrativo o legislativo, o las actuaciones de otro órgano jurisdiccional, tiene el especial deber de controlar el cumplimiento de las normas internacionales por parte de dichos órganos.

Arriba se explicaba cómo el sentido natural de los instrumentos internacionales consiste en limitar el ejercicio del poder estatal. Lo anterior no significa que los particulares se encuentren liberados de respetar los mismos derechos, sino sólo que el principal destinatario de esas obligaciones es el Estado, que asume la obligación de impedir que los particulares restrinjan el ejercicio de los derechos internacionalmente reconocidos. Este sentido vertical de las obligaciones, reforzado por la doctrina de la unidad de la responsabilidad estatal por incumplimiento de las normas internacionales, pone especial confianza en los jueces como contralores del cumplimiento de las obligaciones estatales internacionales. Este deber de control se concreta procurando compatibilizar o armonizar los parámetros internos con los internacionales. En el caso chileno, esta obligación se complementa perfectamente con el deber que el artículo $5^{\circ} \mathrm{CPol}$. impone a todos los órganos que ejercen soberanía, según el cual los derechos esenciales también encuentran sustento positivo en instrumentos jurídicos internacionales.

De acuerdo con este postulado, los jueces no pueden descartar a priori la normativa internacional como medida de enjuiciamiento de la actividad estatal. En efecto, no se trata solamente de cumplir con una norma de carácter internacional, sino también con una obligación positiva nacional como es la que impone el artículo 5 constitucional. De aquí resulta el deber de ajustar, en la medida de lo posible, la aplicación de las normas nacionales a los mandatos internacionales. Este deber ha sido lateralmente reconocido por nuestra jurisprudencia constitucional-como obiter dictum en alguna sentencia del Tribunal Constitucional (sentencia rol No 558, prevención ya citada de la Magistrada Peña) - y persistentemente defendido por el Profesor Nogueira en varios de sus trabajos dedicados al tema ${ }^{60}$. Un ejemplo notable, que sirve para ilustrar esta función complementaria de los instrumentos internacionales, se encuentra en una sentencia reciente de la Corte de Apelaciones de Antofagasta. Como se sabe, durante los últimos

${ }^{60}$ Nogueira, Humberto, Lineamientos de interpretación constitucional y del bloque constitucional de derechos (Santiago de Chile, Librotecnia, 2006), p. 381, ahora en Derechos fundamentales y garantías constitucionales (Santiago de Chile, Librotecnia, 2008), p. 236. 
años se ha discutido sobre la revisión de la decisión judicial penal que se pronuncia sobre las medidas alternativas que establece la Ley No 18.216. Cierta jurisprudencia consideró que, al haberse derogado las normas que permitían la apelación respecto de esta parte de la sentencia penal, la decisión del juez no admitía recurso alguno ${ }^{61}$. Por lo que se refería al recurso de nulidad del nuevo proceso penal, algunas sentencias llegaron a sostener una curiosa tesis: esa parte de la decisión no formaba parte de la sentencia y, por lo tanto, contra ella no cabía la pretensión anulatoria. La Corte de Apelaciones de Antofagasta, en sentencia de 11 de junio de 2008, rol No 103-2008, resolvió, aplicando los artículos 8.2 CADH. y 14.5 PIDCP., que el concepto de debido proceso obligaba a los sentenciadores a considerar el pronunciamiento sobre los beneficios de la Ley No 18.216 como "parte integrante de la sentencia condenatoria" ${ }^{2}$.

Otro ejemplo interesante de complementación de la parte dogmática de la Constitución a través de los tratados internacionales, lo constituye la sentencia del Tribunal Constitucional, de 13 de mayo de 2008, rol No 834. En este caso se discurre sobre la existencia del derecho a la identidad personal del siguiente modo: "sobre el particular, ha de tenerse presente que aun cuando la Constitución chilena no lo reconozca expresamente en su texto, ello no puede constituir un obstáculo para que el juez constitucional le brinde adecuada protección. Lo anterior, precisamente, por su estrecha vinculación con la dignidad humana y porque tampoco puede desconocerse que él si se encuentra expresamente protegido en diversos tratados internacionales ratificados por Chile y vigentes en nuestro país" (considerando $22^{\circ}$ ). Al margen de la precisión con que los convenios que cita el Tribunal reconocen el citado derecho -que podría cuestionar si se trata de otro caso de subversión semántica de la normativa internacional- el ejercicio del Tribunal resulta interesante en la medida en que expresamente apuesta por el enriquecimiento del principio de la dignidad humana a través de su complemento con el Derecho internacional.

Aunque no es una materia que corresponda a este trabajo, cabe sugerir

${ }^{61}$ El asunto llegó a ser parcialmente resuelto por el Tribunal Constitucional, véase la sentencia de 12 de abril de 2007, rol No 670 .

62 "Debe dejarse establecido que el pronunciamiento perjudicial para el imputado respecto del cumplimiento de las penas privativas de libertad referido a los beneficios de la Ley No 18.216 es parte integrante de la sentencia, que los tratados internacionales y el concepto de debido proceso según la Constitución, lo consideran, por lo tanto, no corresponde -ni en el espíritu, ni en la letra de la ley- excluir del recurso de nulidad a estos conceptos referidos a [sic] la ley en comento" (cons. $3^{\circ}$ ), redacción del ministro titular Oscar Clavería. Agradezco el dato aportado por el profesor Ignacio Barrientos Pardo. 
que en el alcance de esta obligación estatal de limitar el ejercicio de las competencias por el respeto de los derechos reconocidos en los tratados, combinada con las nuevas características de la acción de inaplicabilidad, reposa una de las mayores proyecciones del Derecho internacional como parámetro de control de la actividad judicial. En efecto, si es cierto que tras la reforma introducida por la Ley No 20.050 se desplazó el eje de la inaplicabilidad desde la formulación de la norma hacia el control de la aplicación de las normas ${ }^{63}$, resulta que la inaplicabilidad ya no obliga al juez a plantearse la supuesta jerarquía constitucional del tratado como premisa necesaria para dictar la sentencia definitiva. La norma constitucional, como es conocido, ya no obliga al Tribunal Constitucional a pronunciarse sobre la existencia de un "precepto legal contrario a la Constitución" (texto anterior a la reforma), sino sobre "un precepto legal cuya aplicación [...] resulte contraria a la Constitución”. Para constatar esta última condición, bastaría con advertir que el precepto legal puede aplicarse (o se ha aplicado en alguna instancia de la gestión judicial pendiente) violando la obligación del artículo 5 inciso $2^{\circ} \mathrm{CPol}$., dando así lugar a la pretensión de inaplicabilidad. $\mathrm{O}$, a la inversa, para desestimar dicha pretensión sería suficiente indicar que el precepto admite una interpretación que, en forma coherente con los tratados internacionales, descarte la infracción al artículo 5 citado. Esta última técnica, sentencias desestimatorias condicionales de inaplicabilidad, ha sido aplicada alguna vez por nuestro Tribunal (aunque limitando la argumentación a la normativa constitucional interna $)^{64}$.

d) El problema de los valores. En el proceso de interpretación del Derecho internacional de los derechos humanos el operador debe resistirse a aplicar el método, corriente en sede nacional, que concibe a los derechos fundamentales como valores.

La doctrina y la jurisprudencia constitucional nacional, particularmente la de nuestro Tribunal Constitucional, ha recibido con notable entusiasmo la concepción axiológica de los derechos fundamentales. La sentencia del Tribunal Constitucional, de 26 de junio de 2008, rol No 976 (conocida como el fallo "Peña Wasaff”) es un estupendo ejemplo de ello. Como se sabe, esta concepción de los derechos ha sido objeto de profundas críticas en la literatura comparada y nacional, las que ciertamente no cabe recor-

${ }^{63}$ Véase mi trabajo: El control de la igualdad en la aplicación de la ley como factor de expansión del control concreto de constitucionalidad de las leyes, en Fermandois, Arturo (editor), Sentencias destacadas 2007. Una mirada desde la perspectiva de las políticas públicas (Santiago de Chile, Libertad y Desarrollo, 2008), pp. 123-161.

${ }^{64}$ Véanse, por ejemplo, las sentencias de 21 de agosto de 2007 , rol No 739 y de 13 de mayo de 2008, rol No 993. En ambos casos el Tribunal anuda la aplicación legítima de un determinado precepto a una determinada interpretación de la ley. 
dar aquí. Lo importante es tener en cuenta que si esta concepción resulta discutible en el plano interno, en el plano internacional es simplemente inaplicable. La razón es muy sencilla: los instrumentos internacionales no pueden ni deben pretender cristalizar valores. En efecto, los valores constituyen un metalenguaje que condiciona el sentido de las palabras, al extremo que no es improbable que sea precisamente la polisemia de los términos (condicionada por ese metalenguaje) la que facilita el consenso sobre los mismos. A este respecto, la anécdota que relata Maritain sobre la Declaración de derechos de Naciones Unidas es aclaradora: "se cuenta que en una de las reuniones de la Comisión Nacional de la UNESCO, en la que los derechos humanos estaban siendo discutidos, alguien manifestó sorpresa frente al hecho de que algunos paladines de ciertas ideologías violentamente opuestas habían acordado una lista de aquellos derechos. 'Sî', dijeron, 'nosotros estamos de acuerdo en los derechos, pero a condición de que no se nos pregunte por qué. Este 'porqué' es donde la discusión comienza"65.

De acuerdo con lo expresado, los derechos reconocidos en los instrumentos internacionales no dan cuenta de un consenso universal, ni siquiera regional, en materia de derechos humanos y sus fundamentos. Ellos, por el contrario, consolidan mínimos, bajo y sobre los cuales persiste la diversidad y el pluralismo jurídico. Como lo explica el profesor Aldunate, en una obra reciente dedicada al estudio de los derechos fundamentales, los derechos fundamentales recogidos en las constituciones "registran el desarrollo y los pasos del proceso político de la respectiva comunidad, y sus consensos acerca de la base de legitimidad jurídica del ejercicio de la autoridad. Expresan, de esta forma, una individualidad propia, la de la correspondiente e incomunicable historia política plasmada en la Constitución y su desarrollo posterior [...]. Los derechos consagrados en tratados internacionales, por el contrario, representan una suerte de estándar que la comunidad internacional -o la de los respectivos Estados partes- acuerda imponer a los Estados, como obligaciones para los mismos, expresando de este modo, no las particularidades de cada sistema, sino los elementos compartidos, comunes, del ethos jurídico imperante" ${ }^{66}$.

\section{La posibilidad de renacionalizar el discurso: el respeto hacia el principio} de la identidad constitucional nacional.

La internacionalización del Derecho constitucional es un camino de dos

${ }^{65}$ Maritain, Jacques, Introduction, en Unesco (editora), Human Rights Comments and Interpretations (London-New York, Wingate, 1947), p. 9.

${ }^{66}$ Aldunate, Eduardo, Derechos fundamentales (Santiago de Chile, LegalPublishing, 2008), p. 124. 
vías. A lado del sendero que permite abandonar el discurso argumentativo nacional hay otro camino por el que, en ciertos casos, se regresa. A través del primer camino, el razonamiento de los derechos se internacionaliza o, dicho de otro modo, se desnacionaliza. A través del segundo, la argumentación se renacionaliza.

Alejandro Álvarez, uno de los más influyentes internacionalistas chilenos, estudió con extraordinaria profundidad el concepto de "psicología de los pueblos" ${ }^{67}$ y su incidencia sobre las relaciones internacionales. Aunque no alcanzó a observar el desarrollo que, a partir de fines de la década de los sesenta, adquirió el Derecho de los derechos humanos, la prevención del jurista y diplomático mantiene completamente su vigor en el siglo XXI: el Derecho internacional no puede despreciar la relevancia de la identidad de los pueblos. Este deber de respetar la identidad de los pueblos se traduce contemporáneamente en el deber de los organismos internacionales de respetar la identidad constitucional de los Estados. Esta identidad puede entenderse en dos sentidos. En un sentido formal la identidad se conecta con la personalidad del Estado, esto es, su existencia como sujeto autónomo en el Derecho internacional (lo que suele resumirse como la "estatalidad"). En un sentido sustancial, la identidad se refiere al conjunto de rasgos que singulariza, en el plano jurídico-político, las opciones fundamentales de una comunidad frente al resto de los estados y organizaciones internacionales o supranacionales. En virtud de dicha obligación los Estados (o sus élites, como con fuerte realismo sugería Álvarez ${ }^{68}$, pueden mantener sus peculiares concepciones acerca de la vida, la dignidad, la libertad, la propiedad o la solidaridad, por mencionar algunos de los conceptos fundamentales del pensamiento político de los últimos tres siglos que inciden sobre la interpretación de los derechos fundamentales.

El sustento del deber de respetar la identidad nacional, dentro de los márgenes que legítimamente reconoce la diversidad, se encuentra en último término en el principio de subsidiariedad. En virtud de dicho principio, se reserva a los Estados el juicio sobre aquellos aspectos que precisan tomar una posición particular respecto de problemas que no admiten soluciones universales. Los derechos del no nacido, el aborto por libre determinación de la madre, la eutanasia, la moral, el concepto de buenas costumbres, el matrimonio entre personas del mismo sexo parece ser, entre otros, buenos ejemplos de asuntos que conviene dejar a los Estados. Sólo a la luz de la identidad nacional, concretada en una constitución política y jurídica,

${ }^{67}$ Álvarez, Alejandro, El nuevo Derecho internacional en sus relaciones con la vida actual de los pueblos (trad. R. Peña, Santiago, Editorial Jurídica de Chile, 1962), pp. 122 ss.

${ }^{68}$ Ibíd., p. 126. 
es posible dar una respuesta que no disuelva el sentido de comunidad que tienen los convenios y organizaciones internacionales vinculados a la defensa de los derechos humanos. En el orden procesal, este principio se cumple a través de la llamada doctrina del margen de apreciación, según la cual los organismos internacionales de supervisión aplican una suerte de principio de deferencia hacia la solución nacional.

En el orden nacional, el respeto hacia la identidad de la propia Constitución, encuentra aplicación en dos campos fundamentales, la interpretación y la reforma de la Constitución. En el primer ámbito, los operadores jurídicos deben interpretar y aplicar el Derecho sin traicionar esa suerte de telón de fondo que, en el caso chileno, está representado por las Bases de la institucionalidad. En el último ámbito, la doctrina reconoce que no es posible revisar la Constitución, alterando aquellos aspectos que le son consustanciales, sin convocar el ejercicio del llamado poder constituyente originario. En el plano específico de los derechos constitucionales, la doctrina comparada ha desarrollado el concepto de identidad constitucional ("constitutional identity", "identité constitutionnelle", "Verfassungsidentität", etc.) para limitar la argumentación judicial basada en el Derecho comparado $^{69} \mathrm{y}$, a través del concepto de "contra límites" o "límites a la realización de los valores internacionalistas", para identificar aquellos elementos irrenunciables del ordenamiento jurídico interno ${ }^{70}$ que restringen el deber de obediencia al Derecho internacional.

Los contornos del concepto de identidad constitucional y su proyección en el Derecho nacional e internacional no pueden ser abordados en este trabajo. Baste con mencionar que, como criterio metodológico interno, el deber de respetar la identidad de la propia Constitución obliga al juez a modular su deber de conciliar la aplicación de las normas nacionales con el cumplimiento de las internacionales. Este deber de conciliación exige la concordancia recíproca de ambos órdenes normativos, lo que significa que no sólo debe ajustarse la interpretación y aplicación de la normativa interna a la internacional, sino que la interpretación y aplicación de esta

${ }^{69}$ En este sentido, véase: McCrudden, Christopher, Human Dignity and Judicial Interpretation of Human Rights, en The European Journal of International Law 19 (2008) 4, pp. 697 ss.; LeE, Jack, Interpreting Bill of Rights: The Value of a Comparative Approach, en The International Journal of Constitutional Law, 5 (2007) 1, pp. 133 ss.; y Goldsworthy, Jeffrey, Questioning the Migration of Constitutional Ideas: Rights, Constitutionalism and the Limits of Convergence, en CHoudhry, Sujit (editor), The Migration of Constitutional Ideas (Cambridge, Cambridge University Press, 2006), pp. 125 ss.

${ }^{70}$ Véase: Cartabia, Marta, Principi inviolabili e integrazione europea (Milano, Giuffrè, 1999), pp. 95 ss.; y Guzzeta, Giovanni, Trattati internazionali e giudizio di costituzionalità (Milano, Giuffrè, 1991), pp. 335 ss. 
última debe tener adecuada cuenta de los elementos esenciales del orden constitucional interno. En este sentido, tratándose de aquellas libertades que comprometen la identidad del propio ordenamiento constitucional, el juez nacional debe facilitar la interpretación en clave local de las mismas ofreciendo, en su caso, una versión nacional del derecho contenido en el instrumento internacional. Desde luego, esta obligación no alcanza a todos los derechos, pues hay muchos que no comprometen mayormente la identidad estatal constitucional. Sin embargo, cuando ese compromiso se concreta, el juez evitará dar una interpretación o aplicación a las normas y jurisprudencia internacional que implique una cesión o renuncia de esos elementos de identidad que, en el decir de algunos autores, constituyen el "alma o espíritu de la Constitución"

La casuística nacional ofrece algún caso en que este deber de armonización ha sido tangencialmente abordado. Una categoría de casos está constituida por la jurisprudencia relativa al recurso de protección contra autoridades dotadas de inmunidad de jurisdicción, donde se ha reconocido jurisdicción de las Cortes para sustanciar esa acción constitucional de defensa de derechos fundamentales, armonizando la aplicación de los convenios sobre inmunidad con el respeto de los derechos reconocidos en nuestra Constitución ${ }^{72}$. Una segunda categoría la representa aquella jurisprudencia que ha modulado la aplicación de ciertas libertades reconocidas por el Derecho internacional con los derechos reconocidos y garantizados en los artículos 19 y 20 CPol. Me refiero a la sentencia de la Corte de Apelaciones de Antofagasta, de 4 de marzo de 1998 (rol No 822-08), confirmada por la Corte Suprema en sentencia de 4 de junio del mismo año (rol 11.495). El asunto versaba sobre la aplicación de las libertades de tránsito aseguradas por el Tratado de Paz y Amistad entre Chile y Bolivia del año 1904, todo ello en el contexto procesal de un recurso de protección por infracción del número 8 del artículo $19 \mathrm{CPol}$. (acopio de concentrado de plomo en recintos y vagones del Ferrocarril Antofagasta-Bolivia).

Resolviendo sobre el alcance de las disposiciones del tratado frente a los derechos asegurados por la Constitución de 1980, la Corte nortina afirmó que, con la relación entre el tratado y los derechos constitucionales "se

${ }^{71}$ Linares Quintana, Segundo, Tratado de interpretación constitucional (Buenos Aires, Abeledo Perrot, 1998), pp. 289 ss.

${ }^{72}$ Véanse las sentencias de la Corte Suprema, 18 de julio de 1988, rol No 12.595, "Walter Szurgelies Hoyer y Mathilde Selent Ritz de Szurgelies con Primer Consejero de la Embajada de la República Federal Alemana en Chile Hans Ulrich Spohn" (recurso de protección); y 21 de julio de 1988, rol № 12.419, "Manfred Skrabs Naujoks y otros con Horst Kriegler, Cónsul de la República Federal de Alemania en Concepción” (recurso de protección). 
reconoce la superioridad de las garantías individuales, al tenor de lo dispuesto por el artículo $5^{\circ}$ inciso $2^{\circ}$ de la Constitución Política de la República. De manera entonces, que si bien, el Tratado de Paz y Amistad de 1904 garantiza el más amplio y libre derecho de tránsito comercial, su alcance y extensión debe ser interpretado en armonía con la disposición señalada. Debe adecuarse además, al artículo 20 del mismo cuerpo legal, ya analizado [Constitución política], $y$, finalmente debe ajustarse al artículo $19 N^{\circ} 21$ y $N^{\circ} 24$ inciso $2^{\circ}$ de la misma Constitución" (considerando $9^{\circ}$ ). El caso es doblemente interesante, pues los derechos reconocidos en el "Acuerdo de Paz" con Bolivia se asemejan, guardando las distancias, a algunas de las libertades económicas que se reconocen en algunos procesos de integración y que, de acuerdo con la jurisprudencia comparada reciente, se limitan por los derechos constitucionales nacionales interpretados en clave local ${ }^{73}$. En segundo lugar, porque el fallo propone una suerte de diálogo entre ordenamientos, de donde resulta que la aplicación de las libertades reconocidas en un convenio se ajusta y equilibra con los imperativos constitucionales relativos a los derechos fundamentales.

Naturalmente el juez puede, con el consentimiento de sus superiores y sin la crítica del resto de la comunidad política, optar por renunciar a alguna parte de la identidad de la propia Constitución, en cuyo caso la interpretación judicial seguramente daría lugar a una forma de mutación de la Constitución. La identidad, después de todo, es un elemento variable y contingente en las comunidades políticas. Lo relevante, sin embargo, es que el Derecho internacional y la teoría constitucional ofrecen a los jueces un cauce que permite renacionalizar la argumentación, abandonando la senda de la imitación o internacionalización incondicionadas en favor de un discurso limitado, y por lo tanto constitucionalista, del Derecho internacional de los derechos humanos.

El impacto de una decisión nacional que module la interpretación y aplicación de la norma internacional con los imperativos de la Constitución no debe ser dramatizado. En primer lugar, porque no implica, ni necesaria ni automáticamente, una violación del Derecho internacional que genere responsabilidad internacional. Por el contrario, a través de ella el juez nacional cumple de buena fe con un ordenamiento (el inter-

${ }^{73}$ Es precisamente en ese contexto donde se ha desarrollado el deber de deferencia hacia las concepciones nacionales de los derechos fundamentales. Véanse, por ejemplo, los fallos del Tribunal de Justicia de la Comunidad Europea, de 12 de junio de 2003, Asunto C- 112/00, "Eugen Schmidberger, Internationale Transporte und Planzüge v. Austria", y de 14 de octubre de 2004, Asunto C-36/02, "Omega Spielhallen- y Automatenaufstellungs-GmbH v. Oberbürgermeisterin der Bundesstadt Bonn”. 
nacional) que, de suyo, es coherente con el principio de subsidiariedad, y deja abierta la puerta para que los organismos internacionales hagan uso del deber de deferencia expresado a través de la doctrina del margen de apreciación. Por otra parte, es preciso recordar que, en la argumentación de la sentencia, este discurso "re-nacionalizante" en ningún caso debe ser planteado como una declaración frontal de incompatibilidad sustancial del tratado con el ordenamiento constitucional. Lo anterior equivaldría a una declaración formal de inaplicabilidad que le está vedada a todos los tribunales, incluido el Constitucional ${ }^{74}$. En este sentido, parafraseando a Zagrebelsky, conviene reemplazar el discurso conflictivo de la jerarquía por el discurso dúctil de la armonización en el caso concreto y, como se verá más abajo, de la aplicabilidad.

Finalmente, cabe hacer presente la importancia de un aspecto que podría parecer menor: el estilo de la sentencia. Por una parte, una sentencia que evita el lenguaje excluyente de la jerarquía, optando por la armonización de ambos ordenamientos, aleja la posibilidad de la casación o de la nulidad de la sentencia por infracción de ley (en este caso, un tratado). Por otra, del lenguaje depende la resistencia o aceptación de la comunidad frente a los postulados del juez. La doctrina comparada enseńa que el tono con que los jueces redactan las decisiones en que abordan la relación entre el ordenamiento interno y el internacional, o en su caso el supranacional, no es irrelevante. Una sentencia que proponga -incluso implícitamente- la comunión entre ambos ordenamientos y que evite el lenguaje de la confrontación jerárquica es siempre mejor que una decisión que plantee el asunto en términos de todo o nada. Así por ejemplo, el estilo frontal de las admoniciones del Tribunal Constitucional alemán a las autoridades comunitarias europeas ha sido comparado con el estilo más sutil de la jurisprudencia italiana. Como se sabe, en varias sentencias el Tribunal Constitucional alemán ha declarado poseer la competencia para no aplicar la normativa comunitaria cuando ella no respeta el nivel mínimo de derechos asegurados por la Ley Fundamental de Bonn o cuando se dicta con vicio de incompetencia. La dureza de esta declaración (que en la práctica no ha pasado de ser una suerte de cave canem) fue causa de profundas críticas por poner en entredicho los pilares fundamentales del ordenamiento jurídico comunitario. La Corte Constitucional italiana, en

\footnotetext{
${ }^{74}$ Véase en este sentido lo que manda el artículo 54 № 1 de la Constitución: "Las disposiciones de un tratado sólo podrán ser derogadas, modificadas o suspendidas en la forma prevista en los propios tratados o de acuerdo a las normas generales de derecho internacional". Siguiendo esa línea, el Proyecto de ley que modifica la Ley orgánica constitucional del Tribunal Constitucional (Boletín No 4059-07), prohíbe la declaración de inaplicabilidad de un tratado (véase la nota 6).
} 
cambio, ha optado por un lenguaje más sutil, indicando que reconoce competencia para controlar la constitucionalidad de las leyes de ejecución de un tratado en caso de contradicción con los principios fundamentales del ordenamiento o los derechos inalienables de la persona humana ${ }^{75}$. Para un comentarista, este último es el estilo del calcio italiano, "refinado, sutil, elegante y a lo sumo defensivo" 76 .

\section{Epilogo.}

Lo dicho hasta aquí obliga a concluir este trabajo con una última reflexión sobre la jerarquía. Durante los últimos años ha ido cobrando fuerza una tesis que sustituye el discurso jerárquico por razones distintas al escepticismo de metaconstitucionalistas y adeptos al pluralismo constitucional ${ }^{77}$. Me refiero a aquella tesis que sostiene que, antes de decidir a priori a favor de uno u otro ordenamiento (como lo aconseja en principio de jerarquía) los jueces deben preferir la aplicación de aquel precepto que mejor protege el ejercicio de un derecho ${ }^{78}$. Esta perspectiva concedería la razón, por lo menos parcialmente, a la tesis desarrollada en el párrafo precedente. En efecto, por una parte, la preferencia por la norma más favorable abandona el discurso de la jerarquía por otro que obliga a examinar el contenido de las disposiciones en aparente conflicto, para dejar libre el paso a aquella norma que mejor protege la libertad. Por otra parte, la decisión acerca de la norma que es más favorable algunas veces requerirá de un simple cálculo cuantitativo (como acontece comparando algunas garantías propias de la libertad personal), en tanto que en otras necesitará de un análisis cualitativo. Este último tipo de análisis obligará al juez a indagar en los elementos propios de la identidad constitucional nacional.

La opción entre la protección de la vida del no nacido y la autonomía individual de la madre, o entre la obligación de respetar la propia vida y el

${ }^{75}$ Véase: Cartabia, Marta, cit. (n. 70), pp. 114 ss.

${ }^{76}$ WeILER, Joseph, L'Unione e gli stati membri: competenze e sovranità, en Quaderni Costituzionali 1 (2000), p. 12.

${ }^{77}$ Véase la bibliografía citada en nota 4.

${ }^{78}$ Véanse en este sentido: CANÇADO, Antonio, El Derecho internacional de los derechos humanos en el siglo XXI (Santiago, Editorial Jurídica de Chile, 2006), pp. 310 ss.; Cumplido, Francisco, La reforma constitucional de 1989 al inciso $2^{\circ}$ del artículo $5^{\circ}$ de la Constitución; sentido y alcance de la reforma, doctrina y jurisprudencia, en Ius et Praxis 9 (2003) 1, pp. 365-374; Navarro, Roberto, Los efectos en el sistema chileno de fuentes del Derecho penal de la incorporación de los tratados internacionales y del fenómeno de la globalización, en Ius et Praxis 1 (2004) 1, pp. 77-111; Nogueira, Humberto, Lineamientos de interpretación constitucional y del bloque constitucional de derechos (Santiago de Chile, Librotecnia, 2006) pp. 381-382, y nuevamente en Derechos y garantías fundamentales (Santiago de Chile, Librotecnia, 2008), pp. 236 ss. 
derecho a disponer de ella, no se decide sobre la sola base de un cálculo de ventajas cuantitativas. Por el contrario, a falta de un acuerdo universal, la elección sólo puede hacerse sobre las premisas particulares de quien tiene el poder de optar. Estas premisas no son otras que las que resultan de la propia versión (es decir, la versión constitucional nacional) de la vida y de la libertad, o la versión que, como diría Álvarez, resulta de la psicología de los pueblos.

\section{CONCLUSIONES}

1. La comparación entre la jurisprudencia de los tribunales ordinarios y la propia del Tribunal Constitucional demuestra que en Chile todavía no es posible hablar de una concepción judicial unitaria respecto a la posición que los tratados internacionales de derechos humanos ocupan dentro del ordenamiento jurídico. La jurisprudencia conservadora del Tribunal Constitucional contrasta con su propia jurisprudencia en materia de Derecho y jurisprudencia comparadas, y con la jurisprudencia de los tribunales ordinarios de justicia.

2. Es posible constatar, en la jurisprudencia del Tribunal Constitucional, por lo menos cuatro conductas en lo que se refiere a la influencia del Derecho internacional: la evasión argumentativa, utilización retórica, utilización como complemento a la parte dogmática de la Constitución y utilización tendenciosa.

3. Sin perjuicio de lo anterior, en la jurisprudencia de inaplicabilidad es posible advertir una larvada forma de conexión entre la infracción a los convenios internacionales y el artículo $5 \mathrm{CPol}$.

4. El lenguaje interno de los derechos fundamentales no es siempre intercambiable con el lenguaje internacional de los derechos humanos. Existen ciertos criterios metodológicos, basados en la no equivalencia textual, teleológica y axiológica, que aconsejan prevención al momento de trasladar significados.

5. El proceso de internacionalización del discurso constitucional de los derechos de la persona es un camino que tiene dos sentidos. Por un sentido se abandona la argumentación nacionalista a favor del Derecho internacional, en tanto que por el otro se renacionaliza legítimamente el discurso a través del recurso a la identidad constitucional estatal.

[Recibido el 10 de diciembre de 2008 y aceptado el 24 de marzo de 2009]. 


\section{BIBLIOGRAFÍA}

Aldunate, Eduardo, Derechos fundamentales (Santiago de Chile, LegalPublishing, 2008).

AlFoRD, Roger, Misusing International Sources to Interpret the Constitution, en American Journal of Comparative Law 98 (2004) 1, pp. 57-69.

Álvarez, Alejandro, El nuevo Derecho internacional en sus relaciones con la vida actual de los pueblos (trad. R. Peña, Santiago de Chile, Ed. Jurídica de Chile, 1962).

Álvarez, José, International Organizations as Law-Makers (New York, Oxford University Press, 2006).

Bernales, Gerardo, Los tratados internacionales, los derechos fundamentales y la jurisprudencia del periodo 1981-1989, bajo el régimen del artículo $24^{\circ}$ transitorio de la Constitución, en Ius et Praxis 9 (2003) 1, pp. 281-327.

BIDART, Germán, Jerarquía y prelación de normas en un sistema internacional de derechos humanos, en AA. VV. Liber amicorum. Héctor Fix Zamudio (San José de Costa Rica, Secretaría de la Corte Interamericana de Derechos Humanos, 1998).

BIDART, Germán, Los derechos 'no enumerados'en su relación con el Derecho constitucional y el Derecho internacional, en MÉndez, Ricardo (coord.), Derecho internacional de los derechos humanos. Memoria del VII Congreso Iberoamericano de Derecho constitucional (México D.F., Instituto de Investigaciones Jurídicas UNAM, 2002), pp. 103-113.

CAnÇAdo, Antonio, El Derecho internacional de los derechos humanos en el siglo XXI (Santiago de Chile, Editorial Jurídica, 2006).

Carozza, Paolo, Subsidiarity as Structural Principle of International Human Rights Law, en American Journal of International Law 97 (2003) 38, pp. 38-79.

Carozza, Paolo, Uses and Misuses of Comparative Law in International Human Rights: Some Reflections on the Jurisprudence of the European Court of Human Rights, en The Notre Dame Law Review 73 (1998) 5, pp. 1217-1237.

Cartabia, Marta, Principi inviolabili e integrazione europea (Milano, Giuffrè, 1999)

Cassese, Antonio, Diritto internazionale (Bologna, Il Mulino, 2006).

Cea Egaña, José Luis, Derecho constitucional chileno (Santiago de Chile, Ediciones Universidad Católica, 2004).

Cumplido, Francisco, La reforma constitucional de 1989 al inciso $2^{\circ}$ del artículo $5^{\circ}$ de la Constitución; sentido y alcance de la reforma, doctrina y jurisprudencia, en Ius et Praxis 9 (2003) 1, pp. 365-374

De Búrca, Gráinne - Gerstenberg, Oliver, The Denationalization of Constitutional Law, en Harvard International Law Journal 47 (2006), pp. 243-262.

Díaz Tolosa, Ingrid, Aplicación de los Convenios de Ginebra por los Tribunales de Justicia chilenos, en Revista Chilena de Derecho 33 (2006) 2, pp. 305-327.

Fatima, Shaheed, Using International Law in Domestic Courts (Oxford \& Portland, Hart, 2005),.

Ferdinandusse, Ward, Direct Application of International Criminal Law in National Courts (The Hague, T.M.C. Asser Press, 2006).

Goldsworthy, Jeffrey, Questioning the Migration of Constitutional Ideas: Rights, Constitutionalism and The Limits of Convergence, en CHoudhry, Sujit (editor), The Migration of Constitutional Ideas (Cambridge, Cambridge University Press, 2006), pp. 115-141.

Gros, Héctor, Los derechos humanos no enunciados o no enumerados en el constitucio- 
nalismo americano y en el artículo 29.c) de la Convención americana sobre derechos humanos, en Anuario Iberoamericano de Justicia Constitucional 4 (2000), pp. 145-172.

Guzzeta, Giovanni, Trattati internazionali e giudizio di costituzionalità (Milano, Giuffrè, 1991).

Koskenniemi, Marti, From Apology to Utopia. The Structure of International Legal Argument (Cambridge, Cambridge University Press, 2005).

Kumm, Mattias, The Legitimacy of International Law: A Constitutionalist Framework of Analysis, en The European Journal of International Law 13 (2004) 5, pp. 907931.

LeE, Jack, Interpreting Bill of Rights: The value of a Comparative Approach, en The International Journal of Constitutional Law, 5 (2007) 1, pp. 122-152.

Linares Quintana, Segundo, Tratado de interpretación constitucional (Buenos Aires, Abeledo Perrot, 1998).

Mac Cormick, Neil, Beyond the Sovereign State, en Modern Law Review 56 (1993), p. $1-18$.

Mac Cormick, Neil, La sentencia Maastricht: soberania ahora, en Debats 55 (1996), pp. 25-31.

Maritain, Jacques, Introduction, en Unesco (editor), Human Rights Comments and Interpretations (London-New York, Wingate, 1947), p. 9-17.

Matus, Jean Pierre, Informe pericial ante Corte Interamericana de Derechos Humanos, sobre aplicación jurisprudencial del Derecho ley 2.191 de amnistía, de fecha 19 de abril de 1978, en Ius et Praxis 12 (2006) 1, pp. 275-296.

McCrudden, Christopher, Human Dignity and Judicial Interpretation of Human Rights, en The European Journal of International Law 19 (2008) 4, pp. 655-724.

Meron, Theodor, Human Rights Law-Making in the United Nations. A Critique of Instruments and Process (Oxford, Clarendon Press, 1986).

Meron, Theodor, Norm Making and Supervision in International Human Rights: Reflections on Institutional Order, en American Journal of International Law 76 (1982) 4, pp. 754-778.

Navarro, Roberto, Los efectos en el sistema chileno de fuentes del Derecho penal de la incorporación de los tratados internacionales y del fenómeno de la globalización, en Ius et Praxis 1 (2004) 1, pp. 77-111

Nogueira, Humberto, Consideraciones sobre el Fallo del Tribunal Constitucional Respecto del Tratado de Roma que Establece la Corte Penal Internacional, en Ius et Praxis 8 (2002) 1, pp. 563-581.

Nogueira, Humberto, Lineamientos de interpretación constitucional y del bloque constitucional de derechos (Santiago de Chile, Librotecnia, 2006).

Nogueira, Humberto, Los derechos contenidos en tratados de derechos humanos como parte del parámetro de constitucionalidad: la sentencia rol $N^{\circ} 786-2007$ del Tribunal Constitucional, en Estudios Constitucionales 5 (2007) 2, pp. 457-466.

Nogueira, Humberto, Una senda que merece ser transitada: la sentencia definitiva de casación de la Quinta Sala de la Corte de Apelaciones de Santiago, rol No 11.8212003, caso Miguel Ángel Sandoval Rodríguez, en Ius et Praxis 9 (2003) 2, pp. 233-236.

NúñEz, Manuel, El control de la igualdad en la aplicación de la ley como factor de expansión del control concreto de constitucionalidad de las leyes, en FERMAndois, 
Arturo (editor), Sentencias destacadas 2007. Una mirada desde la perspectiva de las politicas públicas (Santiago de Chile, Libertad y Desarrollo, 2008), pp. 123-161.

NúÑEz, Manuel, Una introducción al constitucionalismo postmoderno y al pluralismo constitucional, en Revista Chilena de Derecho 31 (2004) 1, pp. 115-136.

Peña, Marisol, Control de constitucionalidad de los tratados internacionales: la experiencia chilena un año después de la reforma de 2005, en Revista de Derecho Público 69 (2007) 1, pp. 497-501.

Peña, Marisol, Cuatro Estudios de Justicia Constitucional (Santiago de Chile, Cuadernos del Tribunal Constitucional, 2007).

Pica, Rodrigo, La Convención Americana de Derechos Humanos y las autoamnistías de los Estados por las violaciones de los derechos humanos. Chile y el caso del DL. 2191, en Estudios Constitucionales 3 (2005) 2, pp. 141-161.

Quel, Francisco, La protección internacional de los derechos humanos: aspectos generales, en Fernández de Casadevante, Carlos (coord.), Derecho internacional de los derechos humanos (Madrid, Dilex, 2007), pp. 97-111.

Rawls, John, The Law of Peoples (Cambridge Mass. - London, Harvard University Press, 1999)

Ribera Neumann, Teodoro, Los tratados internacionales y su control a posteriori por el Tribunal Constitucional, en Estudios Constitucionales 5 (2007) 1, pp. 89-118.

Ríos, Lautaro, La dignidad de la persona, en VV.AA., XXV Jornadas Chilenas de Derecho Público. La dignidad de la persona (Valparaíso, Edeval), I, pp. 51-52.

Rosenfeld, Michel, Rethinking Constitutional Ordering in an Era of Legal and Ideological Pluralism, en International Journal of Constitutional Law 6 (2008) 3-4, pp. 415-455.

Ruiz Tagle, Pablo - Cristi, Renato, La República en Chile. Teoría y práctica del constitucionalismo en Chile (Santiago de Chile, Lom, 2006).

Salinas Burgos, Hernán, Aplicación del Derecho Internacional al caso Choshuenco: Legalidad y seguridad jurídicas vulneradas, en Fermandois, Arturo - García, José, Sentencias Destacadas 2006. Una mirada desde las politicas públicas (Santiago de Chile, Libertad y Desarrollo, 2007), pp. 103-130.

Santoro, Francesca, El aborto ante el Derecho internacional. Principios emanados de organismos internacionales de derechos humanos y Derecho interno (Memoria de Prueba, Universidad Católica del Norte, Escuela de Derecho, 2007).

Silva Bascuñán, Alejandro, Tratado de Derecho constitucional (2a edición, Santiago, Editorial Jurídica de Chile, 2006).

Slyz, George, International Law in National Courts, en Franck, Thomas - Fox, Gregory (editores), International Law Decisions in National Courts (NewYork, Transnational Publ., 1996).

Sonneven, Pál, International Human Rights Standard and the Constitutional Jurisprudence of Transition States en Central and Eastern Europe, en ASIL. Proceedings of the $96^{\text {th }}$ Annual Meeting (Washington, American Society of International Law, 2002), pp. 397-399.

Teitel, Rudy, Transitional Justice (Oxford University Press, New York, 2000).

Verdugo, Mario - Pfeffer, Emilio - Nogueira, Humberto, Derecho constitucional (Santiago, Editorial Jurídica de Chile, 1994)

von Bogdandy, Armin, Pluralism, Direct Effect and the Ultimate Say: On the Relationship between International and Domestic Constitutional Law, en International Journal of Constitutional Law 6 (2008) 3-4, pp. 397-413. 
Walker, Neil, Beyond Boundary Disputes and Basic Grids: Mapping the Global Disorder of Normative Orders, en International Journal of Constitutional Law 6 (2008) 3-4, pp. 373-396.

Walker, Neil, Flexibility within a Metaconstitutional Frame: Reflections of the future of legal authority in Europe, en Jean Monnet Working Paper 12 (1999).

Walker, Neil, The Idea of Constitutional Pluralism, en Modern Law Review 65 (2002), pp. 317-359

WeILER, Joseph, L'Unione e gli stati membri: competenze e sovranità, en Quaderni Costituzionali 1 (2000), pp. 5-14.

Zampas, Christina - Gher, Jaime, Abortion as a Human Right-International and Regional Standards, en Human Rights Law Review 8 (2008) 2, pp. 249-294.

Zolkos, Magdalena, Human Rights and Democracy in the Polish Abortion Debates: Concepts, Discourses, Subversions, en Essex Human Rights Review 3 (2006) 1, pp. $1-21$.

ZúñIgA, Francisco, Comentario a la sentencia en el caso Molco. Corte Suprema de 13 de diciembre de 2006, en Estudios Constitucionales 5 (2007) 1, pp. 521-525. 